\title{
Approach-avoidance Analysis of Rat Diencephalon ${ }^{1,2}$
}

\author{
M. E. OLDS AND J. OLDS \\ Department of Psychology, The University of Michigan, \\ Ann Arbor, Michigan
}

Behavioral reinforcement by stimulation of diencephalic structures is by now well established. Delgado, Roberts, and Miller ('54), after the work of Hess ('54), Gastaut et al. ('52), Kaada, ('51), and Masserman ('41, '42), established negative reinforcement to diencephalic stimulation in the region of the ventral posterior thalamic nuclei. Work of our own (Olds and Milner, '54; Olds, '56, '60) has established positive reinforcement on stimulation in a system based in medial forebrain bundle regions of the lateral hypothalamus and also in the other brain regions tied together by the widely distributed medial forebrain bundle.

Roberts ('58a, b), Brown and Cohen ('59), and Bower and Miller ('58) have indicated some regions where both approach and avoidance are evoked by stimulation of the same point. Brodie et al. ('60) have shown, to the contrary, that some points yielding positive reinforcement in medial forebrain bundle regions of the macaque could not be made to yield any escape or avoidance reactions at all. Lilly ('58) has reported a focal point near the anterior commissure of the macaque where approach was produced by very low stimulation levels, and a point much lower (near the optic chiasma) where escape was produced by very low stimulation levels. In the rat, we ('60) have found points in medial forebrain bundle regions where stimulation produced positive reinforcement only, points in dorsomedial tegmentum where stimulation produced negative reinforcement only, and points in between these two types, where stimulation produced both positive and negative reinforcement.

Questions remain unanswered concerning the pervasiveness of the areas of pure positive reinforcement, of pure negative reinforcement, and of overlap. More spe- cifically, the questions are concerned with which areas are involved in each phenomenon. The present study takes up these questions with respect to diencephalic centers and some bordering regions of midbrain and telencephalon in the rat.

\section{MATERIALS AND METHODS}

Subjects. One electrode pair was implanted in each of 123 male albino rats. (As explained later in the paper, only 96 of the pairs could be tested for both approach and avoidance behavior.) The electrodes were bipolar, twisted silver wires, 0.01 inch in diameter and insulated except for the cross section of the tips. The two tips were separated only by their insulation; since the distance between electrodes was only about 0.003 inches, the pair could be thought of as stimulating at a single point. Each pair was held in a plastic block screwed to the skull, permitting firm attachment of the light lead wires from the stimulator. The placement of the stimulating tips of the pairs was varied $1 \mathrm{~mm}$ from rat to rat in order to form a loose grid of diencephalon and related structures.

A straight line passing from the primary skull marking, bregma, and through the anterior commissure and optic chiasma was used for reference. Points were denoted by (1) their anterior or posterior distance from this line, (2) their lateral distance from this line, and (3) their depth from the surface of the skull, which

\footnotetext{
"Approach" and "avoidance" are used here to denote the two basic directions of behavior with respect to a stimulus, i.e., movement of the animal toward a stimulus or away from it. Thus "approach" comprehends appetitive behavior, positive reinforcement of behavior, self-stimulation; and "avoidance" comprehends aversive behavior, escape behavior, negative reinforcement of behavior.

2 Support for the research reported here came from the U.S. Public Health Service, the National Science Foundation, the Ford Foundation, the Foundation Fund for Research in Psychiatry, and the Wallace Laboratories.
} 
is nearly a plane over the area studied. (All distances were measured in millimeters.) With these coordinates used, the diencephalon extends from 0 to posterior 5 in the anterior-posterior direction, from 0 to 3 in the lateral direction, and from 5 to 8 or 9 in depth. The grid used in the present study runs from anterior 2 to posterior 7 and from depth 5 to 9 , covering lateral planes 1 and 2.

Behavioral procedures. All rats were subjected to four weeks of approach training and testing and then to four weeks of escape training and testing.

The approach (self-stimulation) technique used has been described previously (Olds and Milner, '54). Animals were provided with a 4 " pedal which protruded into the short wall of a box measuring $5^{\prime \prime} \times 11^{\prime \prime} \times 10^{\prime \prime}$. Each time the lever was pressed, a 60-cycle sine-wave stimulus train was produced. The stimulus train lasted no longer than one-half second, but was briefer for a briefer period of lever depression. During the training period a $50-\mu \mathrm{a}$ rms current was used, and animals were allowed to explore at random. A small source of light near the lever tended to increase the rate of random lever pressing during this phase. Without current, baselevel lever pressing ranged from 10 to 50 rph (responses per hour). The rate of lever pressing considered indicative of positive reinforcement was 200 responses during an eight-minute test period, i.e., 1,500 rph. This criteron was chosen on the basis of the frequency distribution of the self-stimulation scores shown in figure 1. Training and testing sessions were composed of six consecutive eight-minute intervals. After two weeks of training, during which the 50-ua training stimulus was used, the approach rate had reached a stable level. From then on, each daily testing session consisted of six eight-minute tests, for each of which the electric current was progressively increased. Thus the current was set at 0 ma for the first test, and at $10,20,30,40$ and 50 ua for succeeding tests. At the beginning of each test, three one-half-second trains of stimulation at the new current level were delivered. Animals rapidly adapted to the series of tests; on the first two or three days, "extinction" behavior appeared during "zero" and "sub- threshold" tests, but thereafter it disappeared almost entirely. After a week of this training, animals which manifested approach behavior at all would begin to do so as soon as the current was raised to some level above $10 \mu \mathrm{a}$, most of them beginning at 20 or $30 \mu \mathrm{a}$. The data produced during the last five days of the second week form the basis for the approach scores presented in the following sections of this paper. On each of these five days, tests were performed at each of the five current levels $(10,20,30,40,50$ ua). In the series of 11 plates, the range of five test scores (one a day for five days) is plotted for each animal as a function of the elcctric current level. For purposes of further discussion, the high points of these ranges were used for classifying animals into groups. The use of these high points can be justified on several grounds: (1) It provided a definite and easily obtainable statistic for each animal; (2) because the same classificatory method was used in all cases, systematic differences could be ascribed only to the different anatomical locations of stimulation; and (3) owing to the possibility of occasional breaks in stimulating leads and to the possible occurrence of seizure states caused by stimulation, it appeared to the investigators that although accidental low points in the range might occur frequently, the accidental occurrence of very high stable response rates would be comparatively infrequent. Since the top of the range was used for classification, a high criterion of approach behavior was established. Therefore, electrodes classified as yielding such behavior yielded some eight-minute rates which were far higher than could ever have been yielded by chance. But because of this high criterion, some electrodes classified as yielding no approach behavior might in fact have yielded such behavior, in a mild form which the classificatory techniques would leave undiscovered. In any event, the agreement of the chosen statistic with other possible statistics can be checked by reference to the ranges plotted in the series of plates.

The escape test was similar but not identical to others previously described (Sidman, '53; Travis and Olds, '59; Olds and Travis, '60). Stimulation was applied 


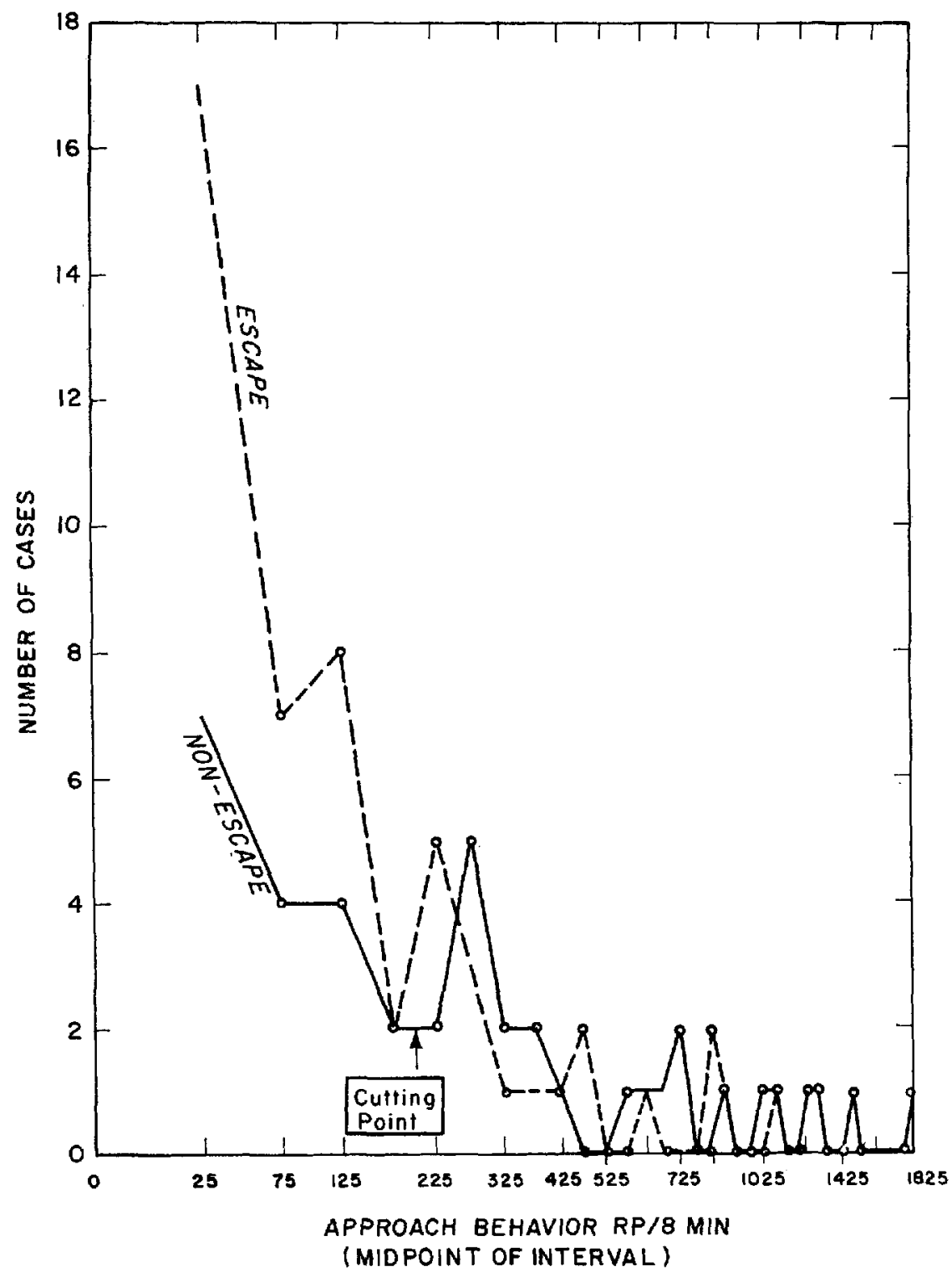

Fig. 1 Frequency distribution showing the number of cases yielding various approach scores. Because the distribution of scores for the non-escape group is bimodal, with 200 $\mathrm{rp} / 8$-min serving as the separation point between the two modes, $200 \mathrm{rp} / 8$-min was chosen as the "cutting point" (i.e., the criterion of approach).

in a continuous series of trains (one-half second on, one-half second off). Whenever the animal pressed the lever, the stimulus series was interrupted or postponed for a four-second interval. This method differs from the Sidman ("53) method only in the brevity of the no- stimulation interval following a response, and in the central rather than peripheral nature of the applied shock.

However, these two differences sufficed to make this far more an "escape" than an "avoidance" test. An "escape" response is one which terminates a stimulus series 
after it has been started, whereas an "avoidance" response is anticipatory, and postpones or prevents a stimulus before it is initiated. The Sidman method, in which peripheral shock is used as reinforcement and 20-second postponement intervals occur after each lever response, yields many anticipatory responses. Sometimes the animal responds so regularly that it may go for long periods without "taking" any shocks at all. The present method, on the other hand, shortens the interval of postponement, and the animals do not avoid so successfully. However, animals do respond quickly after the shock begins.

In the present tests, with a central reinforcing stimulus and a four-second noshock interval, the animals did not make many anticipatory responses. Those with "negatively reinforcing" electrodes often stood quite still during the intervals between stimulation, and then responded quickly after one or several trains when the stimulus series was started again. When the escape response did occur, the animals usually made at least two and sometimes three responses in rapid succession. The second and third responses were relatively ineffective, serving only to lengthen slightly the intervals between stimulations. Afterwards the animals would remain still until the next series of stimulus trains began. The rate of lever pressing considered indicative of negative reinforcement was 180 responses in an eight-minute interval (i.e., 1,350 rph). This criterion was chosen on the basis of the frequency distribution of escape scores shown in figure 2.

The escape series, like the approach series, consisted of six consecutive eightminute tests performed daily. But in the escape series, the electric current was varied from the outset of training, being set during the first week at $5,10,15,20$, 25 and $30 \mu \mathrm{a}$ for all animals. During the second week, animals that failed to respond (hereafter called the high-threshold or EH group) were subjected to a series in which the current was set at 5, 10, 20, 30,40 and $50 \mu \mathrm{a}$. The low-threshold or EL group continued with the series on which they had been started. During the third and fourth weeks, the series were set as follows: $0,10,15,20,25$ and 30 ua for the low-threshold (EL) group, and $0,10,20,30,40$ and $50 \mu$ for the highthreshold (EH) group. The data taken during the fourth week form the basis for the escape scores presented in following sections of this paper. In the series of plates, the range of the escape scores for each animal for the last five days is plotted (like the range of the approach scores) as a function of the electric current level. Correspondingly, the high points of these ranges were used for classifying the animals.

Organization of categories and plates. As shown in figure 3, eight significant entries are provided for each case represented in the plates: (1) the stereotaxic coordinates used for implantation of the stimulating probe; (2) a histological section with an arrow indicating the track left by the probe; (3) a set of abbreviations indicating the authors' theory regarding the structures most likely to have been stimulated; (4) an approach function (SS) with abscissa ranging from 10 to 50 ua rms and ordinate ranging from 0 to 800 responses per eight-minute period ( $\mathrm{rp} / 8-\mathrm{min}$ ), and ranging above $800 \mathrm{rp} / 8$ min when it extends above the allotted box; (5) a numerical score denoting the high point of the range for the approach function; (6) a notation in the escape tests indicating whether low (EL) or high (EH) current levels were used; (7) an escape function with abscissa ranging from 10 to 30 ua for EL and from 10 to 50 ua for EH cases, and ordinate ranging from 0 to $800 \mathrm{rp} / 8-\mathrm{min}$; and (8) a numerical score denoting the high point of the range for the escape function. The ordinates and abscissae are left unmarked in order to save space. They are the same throughout (except for the EL and EH difference mentioned above), which means that all cases can be compared by direct inspection of the curves.

Plates 1, 2 and 3 present cases which met the approach but not the escape criterion; plate 1 presents cases with high approach scores, plate 2 presents cases with medium approach scores, and plate 3 presents cases with low approach scores. Plates 4, 5, 6 and 7 present cases which met the escape but not the approach cri- 


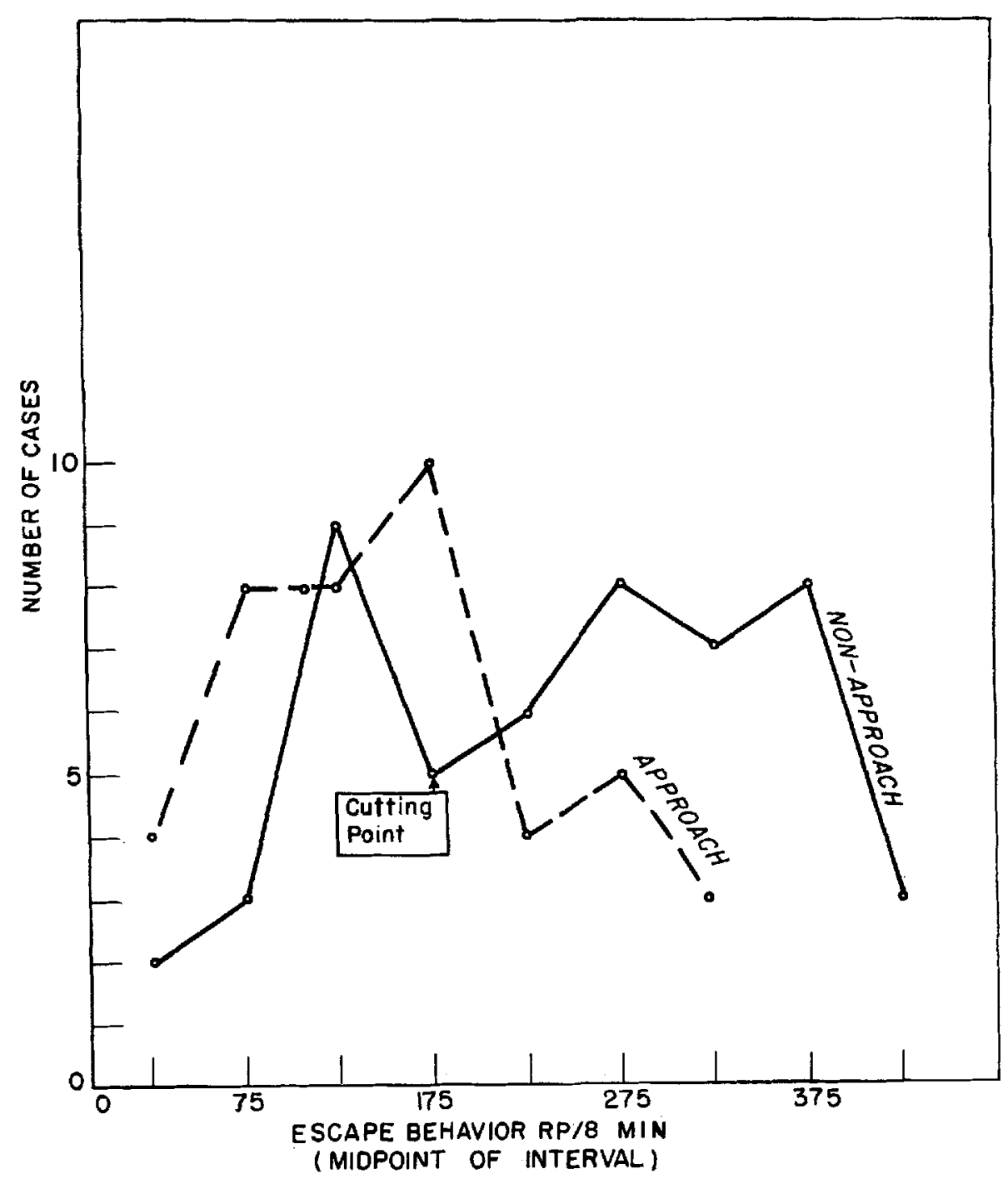

Fig. 2 Frequency distribution showing the number of cases yielding various escape scores. Because the distribution of scores for the non-approach group is bimodal, with 175 rp/8-min serving as the separation point between the two modes, $175 \mathrm{rp} / 8$-min was chosen as the "cutting point" (i.e., the criterion of escape).

terion; plates 4 and 5 present cases with high escape scores, and plates 6 and 7 present cases with low escape scores.

The significance of the behavioral data set forth in these first seven plates is relatively unequivocal. The approach behavior observed cannot easily be attributed to activation from a non-specific drive system; if it could, such activation should also appear in the escape test, but it does not. Similarly, the escape observed cannot easily be attributed to some "extinction phenomenon" or "superstitious behavior" (Skinner, "48) related to the rewarding properties of the stimulation, since during direct tests the stimulation failed to yield any behavior indicative of rewarding properties. The method described in the present paper, in which each electrode is explicitly tested for both kinds 


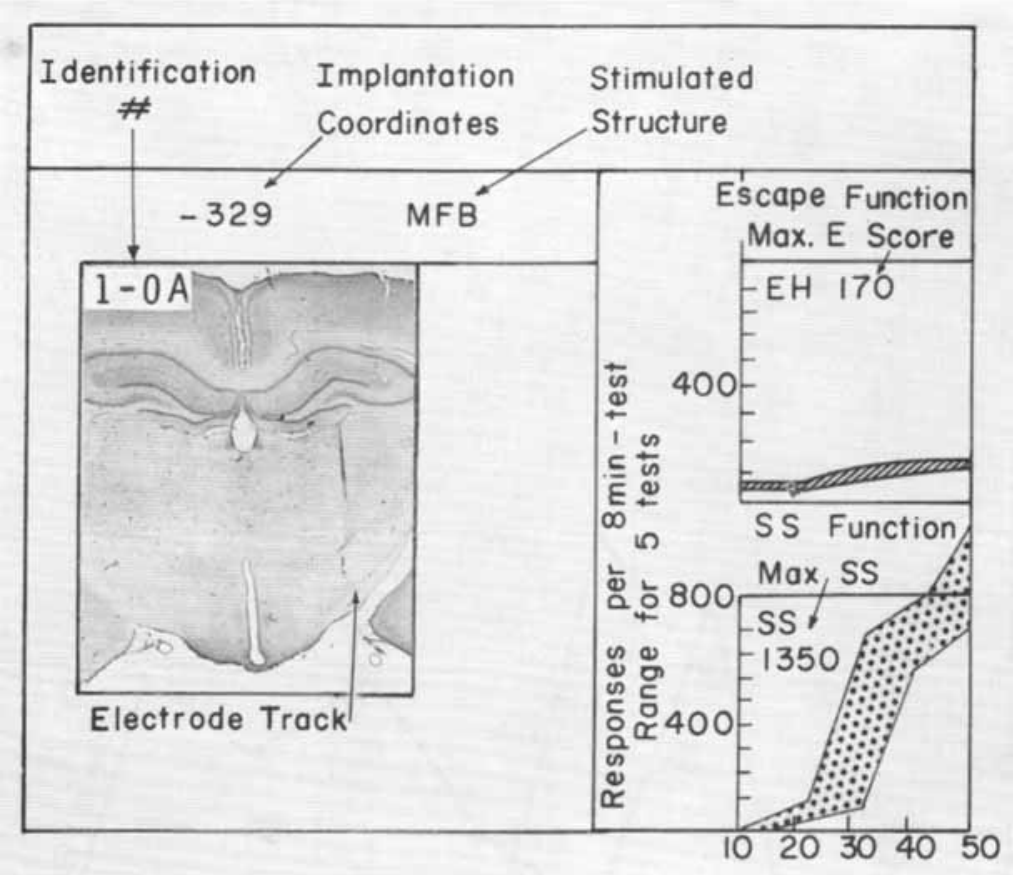

Fig. 3 The data for Case 1-0A, showing how the data are organized for presentation in the 11 plates.

of reinforcement, excludes this source of ambiguity from the unequivocal cases.

Plates 8 and 9 present "ambivalent" cases, which met both approach and escape criteria; plates 10 and 11 present "neutral" cases, which met neither. In all these cases interpretive problems arose. The "ambivalent" cases might have been, for the most part, activated by a brain stimulus which had no particular motivational direction. Another interpretation which secmed reasonable prima facie was that the stimulus presented during the approach tests yielded purely aversive effects which caused responses either by agitating or confusing the animal. Direct observation of the behavior rendered this interpretation implausible, however. Somewhat more likely was the possibility that the stimulus might have yielded mainly rewarding effects with apparent escape responses owing to one of three possible causes, which are given here in order of decreasing likelihood:

(1) If the animal had been previously rewarded for each pedal response and was presented once again with the rewarding stimulus, it responded again as though impelled to sustain, prolong, or augment the stimulus. This interpretation contains elements of the "supersititious" and "extinction" behavior mentioned above.

(2) After overlong stimulation, the motivational sign might have become inverted, as is thought to happen when certain rewarding events are presented in excess.

(3) The animal might have become rapidly habituated to the rewarding event, which would cause it to produce a succession of interruptions because it was more fully rewarded by a succession of starts. However, the likelihood of this possibility was greatly diminished by the fact that the stimulus in escape tests was presented as a series of one-half-second trains (a series of starts and stops) whether the animal responded or not.

The "neutral" cases, which met neither criterion, posed interpretive problems due mainly to the high criteria which had been established. As noted earlier, these high 
criteria excluded some animals yielding possible motivational effect but very slow behavior. Plate 10 presents those cases which met a weaker escape criterion. Plate 11 presents one case which met a weaker approach criterion, three cases which were definitely neutral, and five cases which were ambivalent by a weaker criterion. The possibility of an apparent neutrality caused by mutual cancellation of positive and negative effects was considered but generally rejected because skeletal and autonomic responses yielded by the supposed neutral stimuli were absent.

In the following sections, each animal is designated by a notation indicating the plate, column, and row in which his data appear. Thus data on animal 8-2A appear on plate 8 , column 2 , row $A$. The animal whose data are shown in figure 3 but not in the plates is numbered 1-0A for reference purposes only.

\section{RESULTS}

Of the 123 electrodes implanted, ten fell outside the brain or in the ventricles, and $17 \mathrm{had}$ been tested only for approach behavior before they were accidentally disllodged. Thus 96 in-brain electrodes were tested for stimulus-produced approach and escape behaviors. These 96 electrodes were grouped as shown in table 1 and figure 4.

\section{TABLE 1}

Outcomes for 96 electrodes tested for approach and escape

\begin{tabular}{ll}
\hline Met the approach criterion only & 27 \\
Met the escape criterion only & 34 \\
Met both criteria & 18 \\
Met neither criterion & 17 \\
Total & 96 \\
\hline
\end{tabular}

Twenty-seven electrodes yielded approach behavior with rates of $1,500 \mathrm{rph}$ or more and no marked escape. Thirty-four yielded escape behavior with rates of 1,350 rph and no marked approach. Eighteen yielded both approach and escape behavior at these criterial levels, and 17 yielded neither. There was an inverse correlation between escape and approach scores amounting to -0.35 ; this correlation was significant at the 0.01 level. The correlo- gram with regression lines is shown in figure 4 . The data are given according to anatomic locus in table 2.

Approach behavior. The data on approach behavior are set forth in table 3 . Of 14 cases with rates over $5,250 \mathrm{rph}, 10$ were "pure" (showing no marked escape) and four were ambivalent (showing both approach and escape). Of 15 cases with rates of from 2,950 to 5,250 , nine were pure and six were ambivalent. Of 16 cases with rates from 1,500-2,950, eight were pure and eight were ambivalent.

The series of electrodes which yielded very high rates on approach tests and no marked escape followed the medial forebrain bundle; they were implanted starting at the lateral-most area of the middle hypothalamus and moving medially to the supramammillary area and to a medial region of nearby tegmentum (see fig. 3 and plate 1). Very high approach rates mixed with escape tendencies appeared in anterior medial forebrain bundle regions (8-2A, 8-1B) and in the lateral tegmental region just below the medial lemniscus $(9-2 C, 9-3 C)$. The latter region seems to be the extension of the medial forebrain bundle into tegmentum. Three cases in which electrodes influenced substantia nigra yielded very high approach rates, but since the probes were accidentally dislodged before escape tests could be made, the data are not shown.

The series of electrodes which yielded medium rates on approach tests and no marked escape occupied a region just below and lateral to the septal area, a region proximal to the anterior commissure, and meningeal regions just below the olfactory tubercle or the preoptic area (see plate 2 ). One case (2-3C) of medium approach behavior appeared in the region of the filiform nucleus. Medium rates mixed with escape tendencies appeared in medial regions of the hypothalamus (9-1B, 9-2A, 9-3B), in some internal capsule regions (8-2C, 8-3C), and in boundary regions of the fornix (8-2B).

The series of electrodes which yielded low rates on approach tests and no marked escape appeared first in anterior paraolfactory regions and the septal area, and then in the lateral preoptic area and boundaries between the lateral hypothalamus 


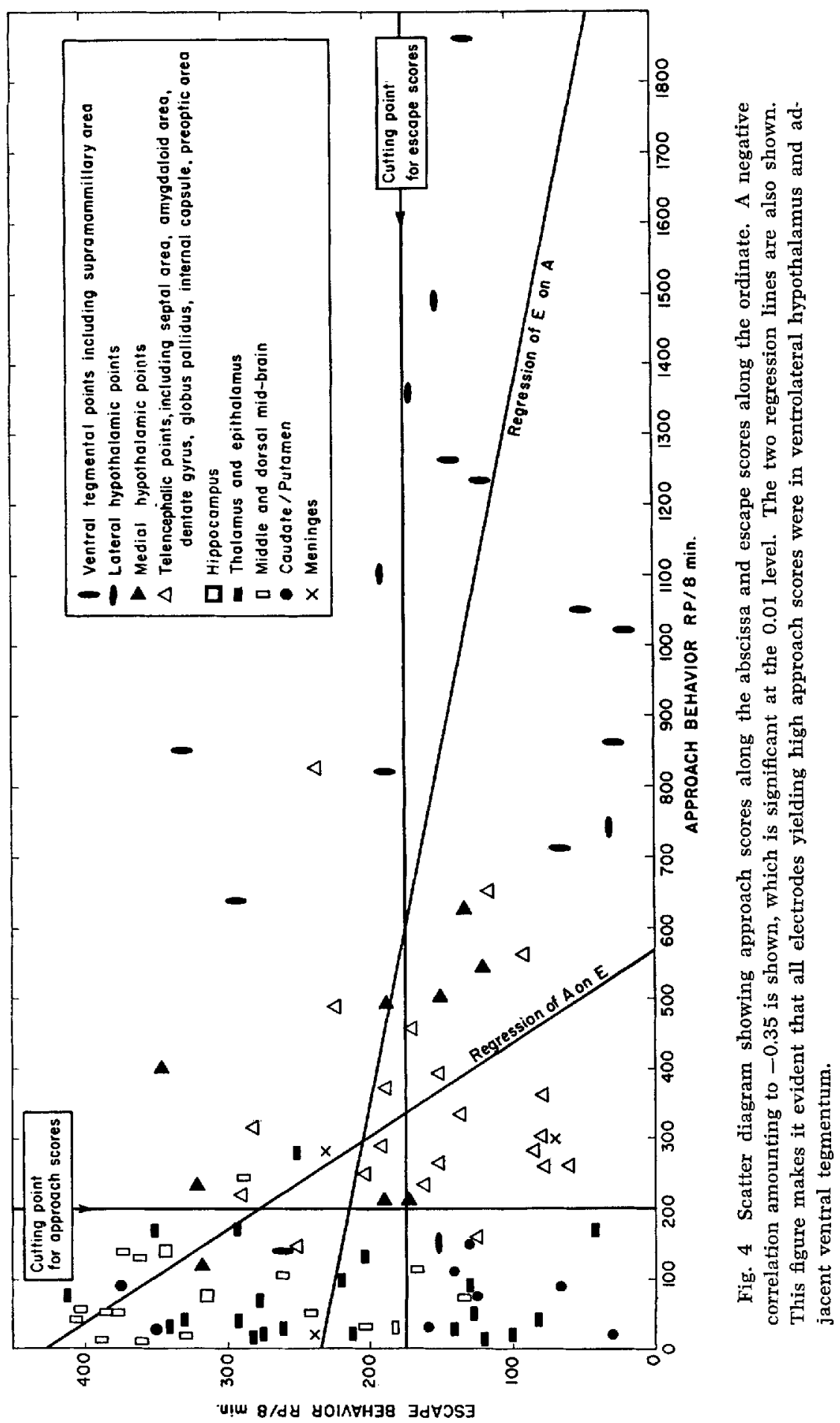


TABLE 2

Array of all self-stimulation and escape scores

according to brain areas stimulated

When several areas were stimulated by the same electrode, the scores produced were listed repeatedly, once for each of the possibly implicated areas. This table provides a key to plates $1-11$, in which the histological material is arranged according to outcome. The column headings are abbreviated as follows:

$$
\begin{aligned}
\text { Abbr }= & \text { abbreviation of name of area } \\
\text { Ident }= & \text { identification number, indicating plate, column, and row on } \\
& \text { which corresponding data appear; e.g., } 2-1 \mathrm{~A}=\text { plate } 2 \text {, column } 1 \text {, } \\
& \text { row } \mathrm{A}
\end{aligned}
$$

Stereo $=$ stereotaxic coordinates used for implantation; e.g., $-725=7 \mathrm{~mm}$

\begin{tabular}{|c|c|c|c|c|c|}
\hline Locus & Abbr & Ident & Stereo & SSt & ESC \\
\hline 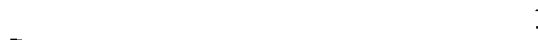 & Telencephalic Areas & & & & \\
\hline \multicolumn{6}{|l|}{ Cortex } \\
\hline Cortex pyriformis & PIR & $2-1 A$ & $029 \mathrm{~A}$ & 450 & 170 \\
\hline Tractus tubercula-piriformis & TP & $\begin{array}{l}2-1 A \\
3-1 A\end{array}$ & $\begin{aligned} & 029 A \\
&+ 228\end{aligned}$ & $\begin{array}{l}450 \\
260\end{array}$ & $\begin{array}{r}170 \\
60\end{array}$ \\
\hline Anterior cingulate & Ant cingulate & $3-2 A$ & +215 & 280 & 85 \\
\hline \multicolumn{6}{|l|}{ Hippocampal formation } \\
\hline Gyrus dentatus (Fascia dentata) & FD & $3-2 \mathrm{C}$ & -315 & 260 & 75 \\
\hline Hippocampus (Cornu ammonis) & HPC & $\begin{array}{l}5-1 C \\
5-2 C\end{array}$ & $\begin{array}{l}-515 \\
-327 \mathrm{~A}\end{array}$ & $\begin{array}{r}50 \\
75\end{array}$ & $\begin{array}{l}380 \\
315\end{array}$ \\
\hline \multicolumn{3}{|l|}{ (Commissura formicis) } & +116 & 290 & 190 \\
\hline Fimbria hippocampi & FI & $4-3 C$ & -125 & 140 & 340 \\
\hline \multirow[t]{2}{*}{ Fornix (Corpus, columna) } & FX & $2-3 C$ & $-117 \mathrm{~A}$ & 625 & 135 \\
\hline & & $3-3 A$ & -115 & 230 & 160 \\
\hline \multicolumn{6}{|l|}{ Septal region } \\
\hline Nucleus accumbens septi & ACB & $3-1 A$ & +228 & 260 & 60 \\
\hline \multirow{3}{*}{ (Area parolfactoria lateralis) } & & $2-1 B$ & $+127 \mathrm{~A}$ & 540 & 140 \\
\hline & & 2-2A & 018 & 390 & 150 \\
\hline & & $11-3 B$ & +217 & 150 & 130 \\
\hline Nucleus medialis septi & MS & $3-1 B$ & 015 & 265 & 150 \\
\hline Nucleus lateralis septi & LS & $3-1 B$ & 015 & 265 & 150 \\
\hline Gyrus diagonalis (Diagonal & DBB & $2-3 A$ & $+229 A$ & 500 & 150 \\
\hline band of Broca) & & $2-1 \mathrm{C}$ & +118 & 500 & 90 \\
\hline Bed nucleus of anterior commissure & $\mathrm{BCA}$ & $8-2 B$ & $+117 \mathrm{~A}$ & 485 & 220 \\
\hline \multirow[t]{3}{*}{ Commissura anterior } & CA & $2-2 A$ & 018 & 390 & 150 \\
\hline & & $2-1 B$ & $+127 \mathrm{~A}$ & 540 & 140 \\
\hline & & $8-2 A$ & 027 & 825 & 235 \\
\hline \multirow{7}{*}{$\begin{array}{l}\text { Paraolfactory tract } \\
\text { Tuberculum olfactorium }\end{array}$} & Para $\mathrm{O}$ & $6-1 A$ & +216 & 150 & 250 \\
\hline & TUO & $2-2 B$ & +129 & 330 & 135 \\
\hline & & 2-3B & +128 & 650 & 115 \\
\hline & & $2-2 \mathrm{C}$ & 019 & 360 & 80 \\
\hline & & $8-3 A$ & $+229 B$ & 250 & 200 \\
\hline & & 3-3B & 029B & 300 & 80 \\
\hline & & $2-1 A$ & $029 \mathrm{~A}$ & 450 & 170 \\
\hline \multicolumn{6}{|l|}{ Basal ganglia } \\
\hline Area amygdaloidea anterior & AAA & $8-3 B$ & $-129 B$ & 220 & 290 \\
\hline \multirow{2}{*}{ Globus pallidus } & GP & $8-2 C$ & 026 & 370 & 190 \\
\hline & & $8-3 C$ & $-317 \mathrm{~B}$ & 315 & 280 \\
\hline \multirow[t]{5}{*}{ Nucleus caudatus/Putamen } & $\mathrm{CPU}$ & $4-1 A$ & 025 & 30 & 350 \\
\hline & & 4-2A & +126 & 90 & 375 \\
\hline & & $11-2 \mathrm{~A}$ & +125 & 90 & 65 \\
\hline & & 11-2B & +227 & 150 & 130 \\
\hline & & $10-1 \mathrm{~A}$ & +226 & 30 & 160 \\
\hline
\end{tabular}
posterior, $2 \mathrm{~mm}$ lateral, $5 \mathrm{~mm}$ deep in relation to bregma

SSt = maximum self-stimulation rate in approach test, $(\mathrm{rp} / 8 \mathrm{~min})$

$\mathrm{ESC}=$ maximum rate in escape test, $(\mathrm{rp} / 8 \mathrm{~min})$ 
TABLE 2 (Continued)

\begin{tabular}{llrrrr}
\hline Locus & Abbr & Ident & Stereo & SSt & ESC \\
\hline & & $10-2 A$ & $+127 B$ & 75 & 125 \\
& & $11-3 A$ & $+225 A$ & 20 & 30 \\
& & $11-1 B$ & $+225 B$ & 110 & 140 \\
Capsula interna & CI & $8-2 C$ & 026 & 370 & 190 \\
Stria terminalis (Taenia semicircularis) & ST & $8-3 C$ & $-317 \mathrm{~B}$ & 315 & 280 \\
\end{tabular}

Lateral

II Hypothalamic Areas

Area preoptica

Nucleus supraopticus hypothalami

Area lateralis hypothalami

Fasciculus medialis telencephali

(medial forebrain bundle)

Zona incerta

\section{Medial}

Area anterior hypothalami

Nucleus paraventricularis hypothalami

Nucleus dorsomedialis hypothalami

Nucleus posterior hypothalami

Nucleus mamillaris lateralis

Nucleus premamillaris dorsalis

Area supramamillaris

Nucleus ventromedialis hypothalami

\begin{tabular}{|c|c|c|c|c|}
\hline POA & $8-2 A$ & 027 & 825 & 235 \\
\hline & $8-1 B$ & 028 & 1100 & 190 \\
\hline & $2-3 A$ & $+229 \mathrm{~A}$ & 500 & 150 \\
\hline & $2-3 B$ & +128 & 650 & 115 \\
\hline & $2-1 C$ & +118 & 560 & 90 \\
\hline & $2-2 C$ & 019 & 360 & 80 \\
\hline & 3-3B & 029 & 300 & 80 \\
\hline & $8-3 B$ & -129 & 220 & 290 \\
\hline LHA & $1-2 A$ & -418 & 1490 & 150 \\
\hline & $3-1 C$ & -318 & 210 & 170 \\
\hline & $8-3 B$ & $-129 \mathrm{~B}$ & 220 & 290 \\
\hline & $11-1 C$ & $-327 \mathrm{~B}$ & 150 & 150 \\
\hline MFB & $1-0 A$ & -329 & 1350 & 170 \\
\hline & $8-1 B$ & 028 & 1100 & 190 \\
\hline & $1-2 A$ & -418 & 1490 & 150 \\
\hline & $1-3 \AA$ & -428 & 740 & 30 \\
\hline & 1-1B & $-518 \mathrm{~A}$ & 710 & 65 \\
\hline & $1-2 B$ & $-518 \mathrm{~B}$ & 1050 & 50 \\
\hline & $9-3 C$ & -728 & 820 & 190 \\
\hline & $2-3 A$ & $+229 \mathrm{~A}$ & 500 & 150 \\
\hline & $3-2 B$ & -219 & 300 & 75 \\
\hline & $3-3 B$ & 029 & 300 & 80 \\
\hline & $3-1 C$ & -318 & 210 & 170 \\
\hline & $7-1 B$ & $-129 \mathrm{~A}$ & 20 & 240 \\
\hline $\mathrm{ZI}$ & $1-1 A$ & -527 & 860 & 30 \\
\hline & $2-3 C$ & $-117 \mathrm{~A}$ & 625 & 135 \\
\hline & $7-1 A$ & -127 & 140 & 250 \\
\hline AHA & 4-3B & -118 & 120 & 320 \\
\hline PVH & $2-3 C$ & $-117 A$ & 625 & 135 \\
\hline & $9-3 A$ & -218 & 210 & 190 \\
\hline & $4-3 B$ & -118 & 120 & 320 \\
\hline DMH & $3-1 C$ & -318 & 210 & 170 \\
\hline & 9-1B & -328 & 400 & 345 \\
\hline PH & 9-1B & -328 & 400 & 345 \\
\hline IML & $3-2 B$ & -219 & 300 & 75 \\
\hline PMD & $9-2 B$ & -419 & 230 & 320 \\
\hline SUM & $1-1 B$ & $-518 A$ & 710 & 65 \\
\hline & $1-2 B$ & $-518 B$ & 1050 & 50 \\
\hline & $1-3 B$ & -528 & 1860 & 130 \\
\hline & $1-1 C$ & -529 & 1020 & 20 \\
\hline & $1-3 C$ & $\begin{array}{r}-119 A \\
\text { (bent) }\end{array}$ & 1230 & 120 \\
\hline VMH & $9-2 A$ & $-119 \mathrm{~B}$ & 490 & 185 \\
\hline & $9-2 \mathrm{~B}$ & -419 & 230 & 320 \\
\hline
\end{tabular}

III Thalamic Areas

Anterior group

Nucleus anterodorsalis thalami

Nucleus anteromedialis thalami

Nucleus anteroventralis thalami

$\begin{array}{lrlll}\text { AD } & 6-1 \mathrm{C} & -217 & 40 & 290 \\ \text { AM } & 4-1 \mathrm{~B} & -227 & 40 & 330 \\ & 6-3 \mathrm{~A} & -117 \mathrm{~B} & 25 & 260 \\ & 10-3 \mathrm{~A} & -216 & 90 & 130 \\ \mathrm{AV} & 4-1 \mathrm{~B} & -227 & 40 & 330 \\ & 6-2 \mathrm{~A} & -126 & 20 & 275 \\ & 10-3 \mathrm{~A} & -216 & 90 & 130\end{array}$


TABLE 2 (Continued)

\begin{tabular}{|c|c|c|c|c|c|}
\hline Locus & Abbr & Ident & Stereo & SSt & EsC \\
\hline \multicolumn{6}{|l|}{ Epithalamus } \\
\hline & HL & $6-1 B$ & -215 & 20 & 280 \\
\hline Nucleus habenularis lateralis & & $6-3 B$ & -415 & 100 & 220 \\
\hline \multirow[t]{2}{*}{ Nucleus habenularis medialis } & HM & $6-3 \mathrm{~B}$ & -415 & 100 & 220 \\
\hline & & $6-1 B$ & -215 & 20 & 280 \\
\hline \multirow{2}{*}{ Stria medullaris thalami } & SM & $6-1 B$ & -215 & 20 & 280 \\
\hline & & $8-1 \mathrm{C}$ & 016 & 280 & 250 \\
\hline \multicolumn{6}{|l|}{ Lateral group } \\
\hline \multirow[t]{4}{*}{ Nucleus lateralis thalami } & LT & $7-2 B$ & -425 & 30 & 180 \\
\hline & & $7-1 \mathrm{C}$ & -225 & 170 & 290 \\
\hline & & $11-3 \mathrm{C}$ & -325 & 170 & 40 \\
\hline & & $10-3 B$ & -526 & 30 & 100 \\
\hline \multirow[t]{2}{*}{ Nucleus lateralis thalami pars posterior } & LTP & $10-2 B$ & -525 & 25 & 140 \\
\hline & & $9-1 \mathrm{C}$ & -626 & 240 & 290 \\
\hline \multirow[t]{3}{*}{ Nucleus posterior thalami } & NPT & $7-2 \mathrm{C}$ & -615 & 130 & 200 \\
\hline & & $10-3 \mathbf{B}$ & -526 & 20 & 100 \\
\hline & & $9-1 \mathrm{C}$ & -626 & 240 & 290 \\
\hline \multirow[t]{2}{*}{ Area pretectalis } & PRT & $7-3 \mathrm{~B}$ & $-625 \mathrm{~A}$ & 30 & 200 \\
\hline & & $10-2 B$ & -525 & 25 & 140 \\
\hline \multicolumn{6}{|l|}{ Medial group } \\
\hline Nucleus paraventricularis thalami & PV & $4-2 \mathrm{C}$ & -416 & 170 & 350 \\
\hline \multirow[t]{2}{*}{ Nucleus parafascicularis thalami } & PF & $4-2 C$ & -416 & 170 & 350 \\
\hline & & $10-1 \mathrm{C}$ & -326 & 15 & 120 \\
\hline \multirow[t]{3}{*}{ Nucleus mediodorsalis thalami } & MD & $6-3 A$ & $-117 \mathbf{B}$ & 25 & 260 \\
\hline & & $6-2 \mathrm{~B}$ & -316 & 20 & 210 \\
\hline & & 10-1B & $-226 \mathrm{~A}$ & 50 & 125 \\
\hline \multicolumn{6}{|l|}{ Reticular } \\
\hline \multirow[t]{4}{*}{ Nucleus reticularis thalami } & RT & $1-1 \mathrm{~A}$ & -527 & 860 & 30 \\
\hline & & $6-2 A$ & -126 & 20 & 275 \\
\hline & & $4-2 B$ & $-317 \mathrm{~A}$ & 75 & 410 \\
\hline & & $7-1 \mathrm{~A}$ & -127 & 140 & 250 \\
\hline \multicolumn{6}{|l|}{ Ventral } \\
\hline Nucleus ventralis thalami & $\mathrm{VE}$ & $11-1 \mathrm{~A}$ & $-226 \mathrm{~B}$ & 40 & 80 \\
\hline Nucleus ventralis thalami pars anterior & VA & 4-1B & -227 & 40 & 330 \\
\hline $\begin{array}{l}\text { Nucleus ventralis thalami pars } \\
\text { dorsomedialis }\end{array}$ & VD & 4-3A & -426 & 30 & 340 \\
\hline Nucleus ventralis thalami pars medialis & VM & $6-2 C$ & -417 & 70 & 275 \\
\hline
\end{tabular}

Tectum

IV Mesencephalic Areas

Brachium colliculi superioris

Commissura colliculi superioris

Nucleus proprius commissurae posteriora (Bed nucleus)

\section{Tegmentum}

Substantia grisea periventricularis (Centralis)

Fasciculus longitudinalis dorsalis (Schutz)

Formatio reticularis (Mesencephali)

Decussatio brachiorum conjunctivorum

Decussatio tegmenti ventralis (ForeI)

Nucleus ruber

$\begin{array}{lrlrl}\text { BCS } & \text { 5-1A } & -725 & 140 & 370 \\ \text { CSC } & 5-2 A & -715 & 15 & 390 \\ \text { NCP } & 5-2 A & -715 & 15 & 390 \\ & 10-2 C & -625 B & 75 & 130 \\ & & & & \\ \text { PVG } & & & & \\ & 1-3 B & -528 & 1860 & 130 \\ & 5-2 A & -715 & 15 & 390 \\ \text { FLD } & 10-2 C & -625 B & 75 & 130 \\ & 5-3 A & -716 & 10 & 360 \\ \text { RF } & 5-3 A & -716 & 10 & 360 \\ & & & & \\ & 9-3 C & -728 & 820 & 190 \\ & 9-1 C & -626 & 240 & 290 \\ \text { DBC } & 4-1 C & -517 & 45 & 405 \\ \text { DTV } & 11-2 C & -427 B & 110 & 170 \\ & 5-3 C & -717 & 20 & 330 \\ \text { NR } & 5-3 C & -717 & 20 & 330 \\ & 1-2 C & -518 C & 1260 & 140 \\ & 9-3 B & -618 & 635 & 290 \\ & 5-1 B & -727 & 50 & 400 \\ & 5-2 B & -627 & 50 & 380 \\ & 5-3 B & -617 & 130 & 360\end{array}$


TABLE 2 (Continued)

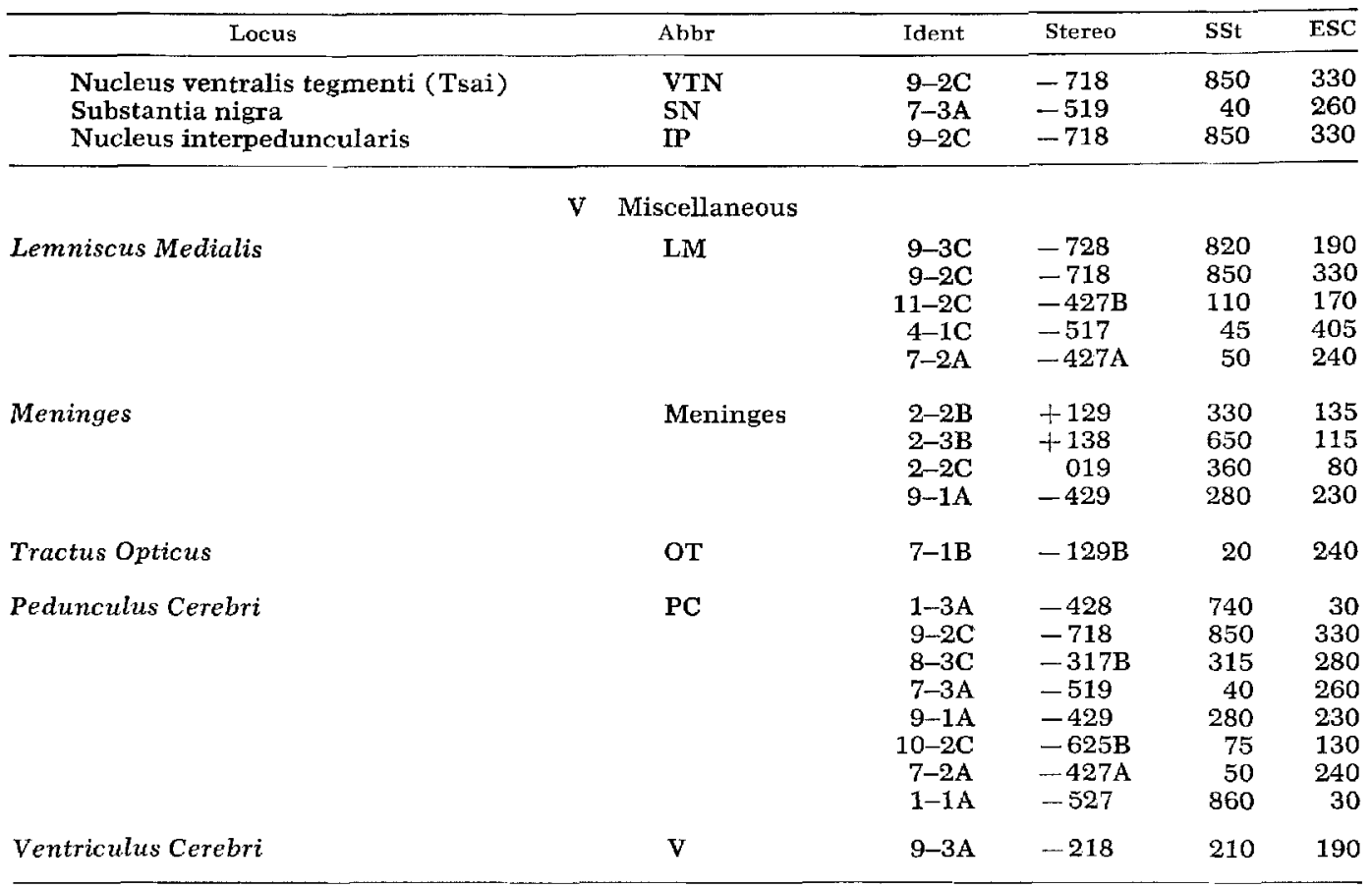

TABLE 3

Outcomes for 45 animals that met the approach criterion

\begin{tabular}{lccc}
\hline $\begin{array}{c}\text { Approach } \\
\text { rate } \\
\text { (rp/8 min) }\end{array}$ & $\begin{array}{c}\text { Number } \\
\text { of animals } \\
\text { yielding } \\
\text { pure } \\
\text { response }\end{array}$ & $\begin{array}{c}\text { Number } \\
\text { of animals } \\
\text { yielding } \\
\text { ambivalent } \\
\text { response }\end{array}$ & Total \\
\hline $\begin{array}{l}\text { High }(700+) \\
\text { Medium }\end{array}$ & 10 & 4 & 14 \\
Low $(200-700)$ & 9 & 6 & 15 \\
Total & 8 & 8 & 16 \\
\hline
\end{tabular}

and optic tract, as well as in hypothalamic regions lateral to the medial forebrain bundle. Similar data were also yielded by electrodes in the dentate gyrus of the anterodorsal hippocampal formation (see plate 3 ). One interesting case which appeared in the dorsomedial caudate also yielded a low approach rate, but since no escape test could be given the data are not shown.

An extensive ambivalent series of electrodes which yielded low rates on approach tests started in mesial tegmentum (9-1C), appeared next in mesial and medial hypothalamus (9-2B, 9-3A), and finally in stria medullaris and septal fornicate areas (8-1C, 8-1A). Similar data were also yielded by extremely ventral electrodes affecting meninges below lateral hypothalamic areas (9-1A, 8-3B, 8-3A).

Escape behavior The data on escape behavior are set forth in table 4 . Of 21 cases yielding rates over $2,250 \mathrm{rph}, 18$ were "pure" (showing no marked approach) and three were ambivalent. Of 31 cases yielding escape rates of from 1,350 to $2,250 \mathrm{rph}, 16$ were pure and 15 were ambivalent.

TABLE 4

Outcomes for 52 animals that met the escape criterion

\begin{tabular}{lccc}
\hline $\begin{array}{c}\text { Escape } \\
\text { response } \\
\text { rate } \\
(\mathrm{rp} / 8 \mathrm{~min})\end{array}$ & $\begin{array}{c}\text { Number } \\
\text { of animals } \\
\text { yielding } \\
\text { pure } \\
\text { response }\end{array}$ & $\begin{array}{c}\text { Number } \\
\text { of animals } \\
\text { yielding } \\
\text { ambivalent } \\
\text { response }\end{array}$ & Total \\
\hline High $(300+)$ & 18 & 3 & 21 \\
Low $(180-300)$ & 16 & 15 & 31 \\
Total & 34 & 18 & 52 \\
\hline
\end{tabular}


The series of electrodes which yielded very high rates on escape tests and no marked approach appeared mainly in the tegmentum just above the medial lemiscus and in periventricular regions and other parts of extreme dorsal tegmentum. The series appeared also in the non-specific structures of the thalamus, and in the hippocampal fornix system (see plates 4 and 5). Very high escape rates mixed with approach tendencies also appeared in the medial-most structures of the hypothalamus $(9-1 B, 9-2 B)$, and in the ventromedial tegmentum (9-2C).

The series of electrodes which yielded low rates on escape tests but no marked approach appeared to occupy boundary regions of the thalamus, including lateral nucleus, posterior nucleus, points in medial lemniscus of the thalamus, and epithalamic points, as well as anterior points in paraolfactory areas. There were also two such points in the ventral cerebral peduncle areas (see plates 6 and 7 ). Low escape mixed with approach behavior appeared with electrodes placed in lower and medial reticular formation (9-1C, 9-3B, $9-3 C)$, the medial hypothalamus (9-3A), epithalamus (8-1C), internal capsule (8$2 \mathrm{C}, 8-3 \mathrm{C}$ ), and anterior paraolfactory regions (8-1 A, 8-1B, 8-2A, 8-2B), as well as with electrodes placed near meningeal boundaries of the hypothalamus (9-1A, 9-2A).

Ambivalent behavior. The group of points which most strikingly yielded both approach and escape behavior (plates 8 and 9) lay in the mid-hypothalamic area (9-1B, 9-2B, 9-3A). Electrodes in the tegmentum also yielded such behavior ( $9-1 \mathrm{C}$, 9-2C, 9-3B, 9-3C), in one case (9-3C) appearing to have influenced both the medial lemniscus and the area just below it. Other ambivalent points appeared to lie on the boundaries of the hypothalamus (8-3C, 9-1A, 9-2A) and of the more anterior olfactory regions (see plate 8 ).

Neutral points. Plates 10 and 11 show a group of supposedly neutral electrode placements. Actually, only three points (11-1A, 11-2A, 11-3A) yielded response rates which were below $750 \mathrm{rph}$ on both approach and escape tests. Of these, two were in the caudate and one was in the ventral nucleus of the thalamus.
Thus almost all points within the diencephalic region studies yielded possible motivational effects of either positive or negative sign or both.

\section{DISCUSSION}

The problem of precisely locating the brain area stimulated by a given electrode remains unsolved. The area is assumed to be some roughly spherical region (almost $1 \mathrm{~mm}$ in diameter for the $50-\mu \mathrm{a}$ stimulus used), most of which is located below the deepest penetration of the electrode track (Olds, '58). The problem of determining within this area the subsection which, when stimulated, yields a particular measured effect is even further from being solved. Therefore, whenever a variety of structures surrounds a stimulating tip, as is usually the case, it is best at first to suspend judgment about the locus of a particular measured effect.

In certain cases, a strategy based on large systems and large numbers can help to circumvent the difficulty. For example, if the set of electrodes maximally yielding a certain effect follows a patterned course through the brain, and if a given anatomic system forms a similar course, a valid correlation of the system with the effect becomes quite probable. Thus, in the present study, the correlation of positive reinforcement with the anatomic system based on the medial forebrain bundle appears to be valid. No such definite statement can be made about negative reinforcement.

At this point the use of behavior rates to measure the intensity of positive and negative reinforcement should be briefly discussed. A critical study (Hodos and Valenstein, '62) based on tests of three rats, each with one electrode pair in the septal area and one in the hypothalamus, purports to show that behavior rate is not a satisfactory measure of the intensity of the reinforcement yielded by stimulation of a particular brain area. This report and others (Olds and Sinclair, '57) make it quite clear that it is possible to generate special cases in which behavior rate does not correlate with other measures of reinforcement. However, when the independent variable is anatomic locus of electrodes and other factors are held constant, prefer- 
ence measures and rate measures have correlated perfectly in indicating one part of the brain as yielding more intense reinforcement than another.

A related question has to do with interaction of the two reinforcing effects and of the two behavior tests. As was suggested earlier in this paper, some general activation resulting from the stimulus might have caused the animals to meet both criteria; some purely aversive effects might have so agitated or confused an animal that it repeatedly pressed the pedal in reward tests; or purely rewarding effects might by some circuitous course have yielded the appearance of aversive behavior.

All such arguments concerning interaction appear far more plausible when considered in the abstract than when considered in relation to the actual results. The main argument against them is the significant inverse correlation of approach and escape scores (see fig. 4). Of the 96 cases tested, 61 (i.e., about $64 \%$ ) met one criterion or the other but not both. Seventeen (i.e., about $18 \%$ ) met neither criterion. Because no argument in this paper is based on the supposed neutrality of these points, they need not be discussed further. The remaining 18 cases (i.e., about $19 \%$ ) were the only truly doubtful ones, and most of the conclusions drawn in this paper can be drawn without reference to them.

At least one argument, however, does depend on the location of some of the points in these 18 cases; therefore a brief discussion of them is appropriate. Two interpretations of interaction need to be considered seriously. The first is that the animal, having once learned to press for the brain-stimulus reward, presses by habit when he is stimulated again. In the present study, this definitely happened when strongly rewarded animals were first put on escape training schedules. But in most such cases this "pseudo-escape" type of response declined as training progressed through the first and second week. By the third week, the behavior of nearly all the animals had stabilized, and it appeared that any considerable amount of escape behavior remaining represented a genuine escape tendency. In some cases of very high approach, however, an escape output reaching criterial levels may well have resulted from residual pedal tendency derived from original reward training. This residual tendency can be conceded without weakening the important finding of a correlation of ambivalent output with midhypothalamic structures, as there were only four such cases (8-1B, 8-2A, 9-2C, 9-3C) and they were not located in midhypothalamic positions. In the mid-hypothalamic cases in which high levels of escape went together with lower approach rates $(9-1 B, 9-2 B, 9-3 A)$, there was no apparent reason for doubt that the escape was real, even though the approach output was substantial in all three cases. Similarly, in the other cases yielding criterial rates of escape together with quite low approach rates, it appeared unlikely that the former were linked in any important way with the latter.

According to the second major interpretation, the stimulus might have been rewarding at first, but might have become aversive when the trains were repeated too often. This interpretation doés not question the aversive qualities of the stimulus, but it does raise the question of how these aversive qualities are affected by the endurance and repetition of the stimulus series. The latter question is not within the scope of this paper, however, and the interpretation itself, which may be valid, does not affect any of our general arguments.

\section{Topographic relations of the systems}

An organized summary of the present data is presented in figure 5; although the summary is somewhat interpretive, it can serve as a basis for further discussion.

Positive reinforcement. Maximal effects were yielded by a telencephalic, diencephalic, and mesencephalic system which forms a " $U$ " in the horizontal plane. The legs of the $U$ are the medial forebrain bundle in telencephalon and diencephalon, and the area under the medial lemniscus in the posterior diencephalon and mesencephalon. The arch is formed by the supramammillary area and similarly placed tissues above the whole region extending from the mammillary body back to the in- 

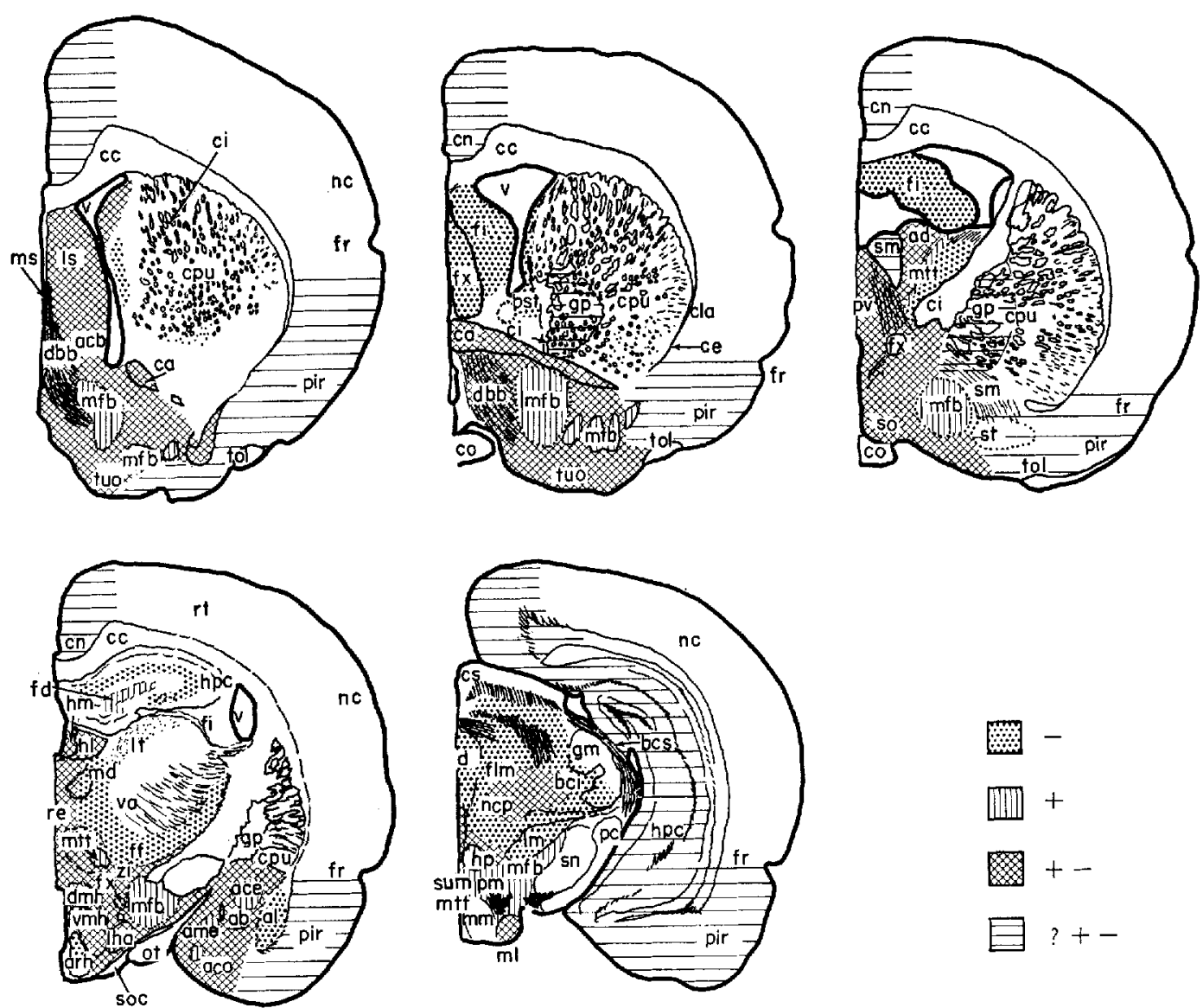

Fig. 5 Theoretical diagram of supposed approach and escape systems and ambivalent areas. The picture is based on the present material and on previous mapping studies (Olds, '56; Olds, Travis and Schwing, '60). Anatomical areas supposed to yield negative reinforcement, positive reinforcement, and ambivalent effects are indicated by dots, vertical hatching, and crosshatching respectively. Areas which are known to yield motivational effects but have as yet been only sparsely explored are indicated by horizontal hatching. Positive reinforcement has definitely been obtained from many points within these areas (Olds, '56). The extent of negative reinforcement obtainable from the same regions is less well known. The brain drawings are based upon the atlas of Massopust ('61).

terpeduncular nucleus. It is not yet definitely established whether or not the interpeduncular nucleus itself forms part of this system, but it is quite certainly established that the medial mammillary nucleus does not (Olds, '56). Regions behind the interpeduncular nucleus have not been systematically investigated. The structures of the mesial and medial hypothalamus contained within the $\mathrm{U}$ yielded attenuated positive reinforcement effects, as did some parts of the caudate, spetal area, epithala- mus, and most of the telencephalic olfactory regions studied.

Ambivalent reactions. Electrodes placed on many of the boundaries of this positive reinforcement system yielded not only attenuated positive reinforcement but escape responses as well. The main region, however, in which electrodes yielded these ambivalent reactions was the group of nuclear masses which make up the medial hypothalamus. It is difficult to treat this whole area, which has long been consid- 
ered the main body of the hypothalamus, as a boundary region of the medial forebrain bundle. In any event, because the area is more than $2 \mathrm{~mm}$ across and because ambivalent reactions occurred right in the middle of it, the contention that ambivalent reactions occur only on the boundaries of the pure positive system is not valid.

Ambivalent reactions also occurred with considerable frequency when electrodes were placed anteriorly in the medial forebrain bundle itself. Pure positive cases were, in fact, extremely rare in the anterior hypothalamus and anywhere in the telencephalon. One can suppose that in these anterior areas the positive system is more diffuse and intermingled with other systems.

Negative reinforcement. The area in which pure negative effects were achieved is best described as it appears on one half of the transverse or coronal plane. In the midbrain, it appears to form a full circle surrounding the reticular activating system. The circle is formed by the brachium of the medial geniculate on the lateral boundary, by the medial Iemniscus below, by the periventricular grey on the medial edge, and by the ventral tectal structures on top. In the thalamus, the system seems to lose its upper boundary, so that it forms a U. The lateral forebrain bundle and some parts of the reticular nucleus form the outer edge of the system, the medial lemniscus still forms the base, and the midline structures of the thalamus form the medial border. In the telencephalon, negative reinforcement appeared somewhere on the boundary of the lateral ventricle (apparently in the caudate), in the vertical fornix column, and in the hippocampus proper. (One electrode that appeared to stimulate the dentate gyrus yielded positive reinforcement.)

\section{Physiological and anatomical considerations}

In considering the function of these areas, it is important to remember that the positive or negative reinforcement yielded by stimulation of a brain point is not to be reified as the "function" residing in some area which contains the point. One has only to remember how many dif- ferent outcomes can be yielded when stimulating or ablating takes place within a single hypothalamic area to realize that no single or exclusive function is residing there. Manipulation of the hypothalamus by stimulation or lesion yields, in one place or another: eating (Delgado and Anand, '53), drinking (Andersson, Jewell, and Larsson, '58), cessation of eating (Anand and Dua, '55a, b), modification of autonomic signs in both sympathetic and parasympathetic directions (Hess, 49), modifications of sexual behaviors (MacLean, Dua and Denniston, '61), modification of temperature regulating mechanisms (Ranson and Magoun, '39), gross activation of behavior (Roberts, ' $58 \mathrm{~b}$ ), gross inhibition of behavior (Hess, '49), and aggressive responses (Masserman, '41). Yet stimulation of almost all hypothalamic regions in rat yields, among other things, the positive reinforcement of operant responding, as exemplified by the approach experiment.

To understand the breadth of the areas yielding approach, it is helpful to remember how primitive and ubiquitons are appetitive and homing reactions. In phylogeny, these reactions first appear together with specific chemoreceptor mechanisms in coelenterates and platyhelminthes (Jahn and Wulff, '50). And in the economics of the complex organism, they subserve in all probability all the basic drives, including hunger, thirst, sex, and temperature. In these cases there are not only autonomic adjustments which contain all elements of feedback within the organism (as when the animal shivers or sweats), but also environmental homing reactions (as when the animal moves toward a warmer environment). Among otherwise diverse drive systems, these approach reactions are a common denominator, as is evidenced by the ubiquity of the approach response in the hypothalamus.

As for the structure of the hypothalamic system yielding positive reinforcement (assuming that the system includes virtually all of the hypothalamus except for the mammillary area), there are two-way connections (1) rostrally with olfactory systems, (2) dorsally with non-specific thalamic systems, and (3) caudally with 
mid-brain and medullary centers. The medial forebrain bundle itself provides one system of two-way connections in the rostral direction (Morin, '50; Ariens Kappers, Huber, and Crosby, '36) and similar lateral fiber systems provide for discharge into tegmental areas (Crosby and Woodburne, '51; Krieg, '32). Other fibers from rostral areas are fed in by the fornix and stria terminalis systems (Ariens Kappers, Huber and Crosby, '36). Other caudal discharge pathways are provided by the periventricular dorsal longitudinal fasciculus system (Crosby and Woodburne, '51; Krieg, '32), which also provides a connection, quite likely a two-way connection (Crosby and Woodburne, '51), to dorsomedial areas of the thalamus. Afferents from tegmental and medullary areas appear to be supplied mainly by the system of fibers known as the mammillary peduncle (Crosby and Woodburne, '51; Ariens Kappers, Huber and Crosby, '36).

With so many interacting pathways to consider, reasonable speculation about the directions of discharge chiefly involved in positive reinforcement is not possible at the present time. But one interesting correlation is worthy of note: In posterior hypothalamus, lesions medial to the mammillothalamic tract and fornix yield degenerations in the tegmentum, whereas lesions lateral to this line do not (Morin, '50). A similar distinction appears in the present data: Electrodes medial to this line yield both approach and avoidance reactions whereas electrodes lateral to this line yield pure approach reactions.

There seems to be even less likelihood of speculating reasonably about the areas which yield negative reinforcement. In view of the possible involvement of the medial geniculate, superior colliculus, medial lemniscus, and ventral thalamic nucleus, it does not seem unlikely that many disparate sensorv systems are involved. Since negative effect might be attached to excessive or obnoxious auditory, visual, gustatory, or somesthetic inputs, this widespread pattern of avoidance effects should not be surprising.

More interesting, perhaps, are the avoidance effects attaching to extrapyramidal and nonspecific systems such as the red nucleus, the nonspecific system of the thalamus, the midline area of the hypothalamus, and the fornix and hippocampus.

The most unified single system involved in the diencephalon and mesencephalon is tied together by the dorsal longitudinal fasciculus, which at its diencephalic end is often referred to as the periventricular system. This unified fiber system appears to project mainly in a dorsal and caudal direction from the medial hypothalamus up toward the medial thalamus, with some fibers also coming back along the same path. It also projects upward and backward from the posterior hypothalamus toward the pretectal, posterior commissure, central gray, and other systems of tegmentum (Crosby and Woodburne, '51).

Perhaps the most significant aspect of our present findings is that by our test, diencephalic systems which project into tegmentum along these pathways always have an ovoidance component; and that systems which fail to project into tegmentum along these pathways often yield purely positive reinforcement.

\section{Previous work}

The approach mechanisms. Previous work on rat indicates maximal positive reinforcement from stimulation in medial forebrain bundle placements of the posterior hypothalamus and ventromedial tegmentum, with slightly milder effects in the medial forebrain bundle of the anterior hypothalamus and in the anterior commissure region. Far milder effects are reported from stimulation in the middle tegmentum, intralaminar and anterior thalamus, septal area, some parts of the caudate, and anterior paraolfactory regions (Olds, '56; Olds, Travis and Schwing, '60; Bower and Miller, '58).

In other mammals the picture is similar. In their studies of cat, Brady ('61), Nielson et al. ('58), Sidman et al. (55), Brown and Cohen ('59), and Roberts ('58b) have found that electrodes in the lateral and mesial hypothalamus yield postive reinforcement with great regularity. The strongest effects are achieved in the area of the medial forebrain bundle. Some parts of the caudate also yield positive reinforcement; some parts of the septal area do not. In a recent dissertation, Wilkinson ('62) 
at Duke University has reported on brain structures of cat tested for both postive and negative reinforcement. The map he draws of positive, negative and ambivalent effects shows particularly at the brainstem level a similarity to figure 5 which can only be regarded as remarkable when it is considered that the work was done on a different species in a different and distant laboratory and in complete indepedence of ours.

In their studies of monkey, Bursten and Delgado ('58), Brady ('61), Lilly ('58), Brodie et al. ('60), and Porter et al. ('59) have found that electrodes in medial forebrain bundle regions yield positive reinforcement of great intensity. On electrical stimulation, paleocortical structures (e.g., orbitofrontal and entorhinal areas) and the amygdala, caudate, globus palidus, lateral septal nucleus, anterior commissure, and nonspecific thalamus are also reported to yield positive reinforcement in varying degrees.

Delgado and Hamlin ('60), Heath and Mickle ('60), and Sem-Jacobsen and Torkildsen ('60) have reported on humans who have had electrodes chronically implanted in the brain for therapeutic purposes. Stimulation of electrodes believed to be in the hypothalamus and tegmentum have produced extreme euphoria; stimulation of electrodes in the septal area have inhibited pain and produced feelings of "well being." Stimulation of electrodes in paleocortical regions of the frontal lobe have produced milder positive reactions.

The escape mechanisms. Previous work on cat and monkey (Delgado, Roberts and Miller, '54; Delgado, '55; Delgado, Rosvold and Looney, '56; Roberts, '58a; Roberts, '58b; Roberts, '62) indicates painlike responses and avoidance responses from a variety of midbrain areas, including the medial lemniscus, spino-thalamic tract, central gray, and trigeminal nerve and its root, and also from a ventral tectal location near the posterior commissure. Similar responses have also been rereported from related structures in the thalamus, namely the ventral nucleus and possibly the lateral and dorsomedial nuclei as well. A fearlike response prodncing avoidance behavior has been definitelv revorted from stimulation in the dorsomedial thala- mic nucleus (Roberts, '62). Similar responses have resulted from electric stimulation applied to the hypothalamus near the ventral aspect of the posterior hypothalamic nucleus, in the Forel H1 field of zona incetra. Rage has been produced with electrodes implanted in the ventromedial nucleus of the hypothalamus, in the fornix, and sometimes in the mamillothalamic tract (Masserman, ' 41 , '42; Roberts, '58b). In rat, stimulation of the ventromedial nucleus of the hypothalamus has produced escape behavior (Olds, '60). Hess ('54) has reported that stimulation of the posterior hypothalamus and midline thalamic nuclei in cat elicits a pattern of attack-defense.

In telencephalic systems, the hippocampal points, fornix system points, and parts of the amygdala have been implicated in negative reinforcement effects of electric stimulation (Delgado, Roberts and Miller, '54; Delgado, '55; Delgado, Rosvold and Looney, '56).

The ambivalent responses. Roberts ('58b) was the first to report on rewarding and punishing effects elicited by stimulating the same electrode at the same intensity. He came upon the effects while investigating the lateral boundary area of the posterior hypothalamic nucleus ('58a), and found that although electric stimulation caused escape behavior after the onset, prior to the onset the animal would not heed a warning signal and avoid. Roberts' first guess was that for some reason the brain stimulus failed to become associated by normal learning mechanisms with the warning signal. Later ('58b), however, he tested the notion that the animal might be rewarded by the onset of the stimulation, but punished by its continuation beyond a certain point. Proceeding on this assumption he found that animals would press a lever to turn the stimulation on, and that they would also respond to turn it off. Still later in this experiment, using a symmetrical $Y$ maze with one alley for turning the stimulus "on," one for turning it "off," and one for leaving it "as is," whether on or off, he found that these animals would work to turn a stimulus on and then to turn it off. At low intensities the turn-on response 
was dependable and the turn-off response nearly random. As the intensity increased, the turn-off response became dependable and the turn-on response became slower and more conflicted.

Roberts concluded that brief or lowintensity stimulation was positively reinforcing, but that with increased intensity or prolonged duration, the postive reinforcement was reduced and negative reinforcement appeared.

In this as in the other approach-escape experiments, identical or roughly similar stimulus intensities were used to test reward and punishment. Characteristically, however, the train duration was fixed at some brief level during reward experiments and was extended in escape experiments until response occurred.

Roberts made a special test ('58b) to study this duration factor. Animals were forced to take either a three-minute train of stimulation or none at all. Under this regime, two animals which had shown milder reward in previous tests chose none at all, and one animal which had previously shown strong reward chose the threeminute stimulus. For two of the animals, therefore, the stimulus was transformed from positive to negative when its duration was extended.

The work of Roberts was followed by that of Bower and Miller ('58), who reported that rats with electrodes implanted in the anterior medial forebrain bundle would work both to approach and to escape from electric stimulation, but that rats with electrodes implanted in the posterior part of this same bundle showed pure approach behavior.

Brown and Cohen ('59) implanted electrodes in the dorsomesial hypothalamus of cat at a point dorsal to the ventromedial nucleus. These points yielded classical "hypothalamic-rage." But the stimulation was rewarding in the sense that cats would respond faster on successive trials to get an 0.3-sec stimulus train. On the other hand they would also act to escape from the stimulus when it was continued up to the time of the escape response. These animals, unlike those tested by Roberts, did learn to heed a warning signal, and eventually many of them re- sponded early enough so that they got no stimulation at all. Brown and Cohen concluded that the stimulus has merely an activating effect devoid of approach or avoidance characteristics. But possibly the data are better interpreted by Roberts' assumption that animals with electrodes in mid-hypothalamus tend to be rewarded by brief stimulation and punished by prolonged stimulation.

Analyzing the tegmentum, Olds and Peretz ('60) found that dorsomedial points and medial lemniscus points caused animals to escape from head stimulation by moving onto an aversive foot grid; in these cases there was no approach behavior. Stimulation in the ventrolateral tegmentum caused no escape response but did cause strong approach behavior; stimulation in areas in middle parts of the reticular activating system caused both escape and approach responses, depending on the nature of the test.

Using the present technique, which does not distinguish between escape and avoidance, Olds ('60) showed that lateral hypothalamic electrodes implanted in the medial forebrain bundle and electrodes implanted in the anterior commissure region would yield reward but not punishment. Electrodes implanted in the ventromedial nucleus of the hypothalamus and in dorsomedial tegmentum yielded escape but not approach. Some electrodes implanted in the mesial (i.e., the mid-lateral) hypothalamus yielded both. In this study, the escape stimulus was more nearly identical with the stimulus used in the approach tests, for the duration of both trains was the same. In escape studies, however, the repetition of trains occurred more frequently, at a rate of one per second unless the trains were stopped for four seconds by an escape response. In approach tests, the response rates of ambivalent rats were never above one response every two seconds. Thus it appears that in this case, applying the stimulus too often had avoidance effects.

In all these cases, it appears that the stimulus became aversive when it was presented immoderately. This view is consistent with an earlier report by Reynolds ('58) of a decline in positive reinforce- 
ment behavior rates at high stimulus levels with electrodes implanted in the ventromedial hypothalamus. Hodos and Valenstein ('62) report a similar decrease in rate at high intensities of stimulation, but they also show that the higher intensity is sometimes preferred even though it produces slower rates of responding. Stein and Ray ('59), on the other hand, seem to support Reynolds' ('58) supposition that positive reinforcement declines at very high levels of stimulation. They report self-regulation experiments in which the animal is permitted to choose the intensity it prefers, and find that with electrodes in posterior hypothalamic or tegmental locations the preference is for less than maximal stimulus intensities. With electrodes in telencephalic septal locations, however, the preference seems to be for maximal stimulation up in the very high range, in which seizures are regularly produced.

The problem of the reversibility of approach behavior has thus far been considered on the basis of changes in the amount of stimulation, i.e., changes in duration of train, number of trains per unit time, or intensity of stimulus. Two papers have appeared which suggest that the reinforcement sign may sometimes be modified by external factors. Nielson et al. ('58) indicate that using a neutral caudate stimulus as a warning signal of oncoming aversive shock converts the caudatal shock itself into an aversive stimulus. Kopa, Szabo, and Grastyan (in press) report that stimulation in diffuse thalamic areas causes increased fearlike behavior in an otherwise dangerous situation, and increased relaxation in an otherwise safe situation.

In summary, in some cases the prime determinant of reinforcement effects is the locus of the stimulating electrode. Thus, stimulation in the anterior commissure region (Lilly, '58; Olds, '60) and in the medial forebrain bundle region (Olds, '60; Brodie et al., '60) seems to produce irreversibly positive reinforcement effects. Stimulation in the dorsomedial tegmentum (Delgado, '55; Delgado, Rosvold, and Looney, '56; Olds, '60), in the medial lemniscus (Delgado, Roberts and Miller, '54; Delgado, '55; Roberts, '58b), in the ventral thalamus (Delgado, Roberts and Miller, '54), in the dorsomedial thalamus (Roberts, '62), and possibly in meningeal or chiasmal regions below the anterior commissure (Lilly, '58) produces irreversibly negative effects.

For other points, particularly in the medial hypothalamus, the amount of stimulation seems to be the prime determinant of reinforcement effects, with brief and low-intensity shock yielding positive reinforcement and high-intensity or longenduring shock yielding negative reinforcement.

Finally, for some points in the caudate and in diffuse systems of the thalamus, associative learning may be one of the prime determinants of reinforcement effects. Points in the paleocortical, amygdaloid, and paraolfactory regions have yet to be explored in order to determine the extent to which the reinforcement sign is reversible. Work of Wurtz and Olds ('61) suggests that in these regions too, some points are irreversibly positive, some are irreversibly negative, and some are changeable, depending on stimulus or on situational or associative factors.

\section{Review of discrepancies}

Insofar as the present results emphasize the medial forebrain bundle for positive reinforcement localizations and the medial lemniscus for negative reinforcement locations, they tally well with previous results (Brady, '58; Lilly, '58; Roberts, '58b; OIds, '56, '60; Olds, Travis, and Schwing, '60). There are several discrepancies that call for discussion, however, first among them being the supramammillary decussation. Two cases of negative reinforcement by stimulation in this area have been observed in previous experiments (Olds, '60; Roberts, ' $58 \mathrm{~b}$ ), with only one case of mild positive reinforcement observed (Olds, '56). But it is in this area that, in the present study, four of the electrodes yielding strongest positive reinforcement were shown to be located. The mass of new evidence impels us to assume that this medial arch of the medial forebrain bundle has been overlooked in previous investigations, and that quite possibly it is a major focal point for the positive effect. 
The second of the discrepancies involves the anterior thalamus. In several previous studies with electrodes placed in the anterior and intralaminar thalamus, positive reinforcement has been reported (Olds, '56; Olds, Travis and Schwing, '60; Lilly, '58). But in the present experiment, the five electrodes placed in the anterior thalamus not only failed to yield positive reinforcement but consistently yielded negative reinforcement. Both the previous and the present data seem to be unexceptionable, and it is unlikely that all previous anterior thalamic electrodes could have been located in one system and all the present ones in another simply by chance. Some aspect of the testing procedure must be involved, but it is not at all clear which. The most likely explanation is based on a report (Kopa, Szabo and Grastyan, in press) that stimulation by electrodes chronically implanted in diffuse systems of the thalamus causes no characteristic emotional tone of its own but rather seems to accentuate whatever the background tone may be. These investigators report that stimulation in a dangerous situation causes a fear response, whereas stimulalation in the home cage causes reactions suggestive of rest and restitution. Such evidence suggests that animals might approach anterior thalamic stimulation in otherwise positive situations and avoid it in otherwise negative ones.

Third in the list of discrepancies is the ventromedial nucleus of the hypothalamus, where stimulation has been reported to have positive effects (Olds, '56; Lilly, '58) and in a more recent study (Olds, '60), pure negative effects. The present study shows only a single case in which a hypothalamic electrode did not reveal at least some evidence of positive reinforcement. All medial hypothalamic electrodes without exception showed evidence of both positive and negative reinforcement. This finding neither confirms nor conflicts with the recent report of pure negative reinforcement in the ventromedial nucleus (Olds, '60), as no electrode in the present study was definitely located in the ventromedial nucleus. However, the present work does suggest that to a very large extent all medial hypothalamic areas in front of the mammillary body yield both positive and negative reinforcement.

Finally, the present results show cases in which negative reinforcement was apparently produced by electrodes located in the red nucleus. We know of no previous report which implicates this area in negative reinforcement at all, yet in the present study, the three electrodes in the red nucleus yielded the most pronounced negative reinforcement. Roberts ('58b) reported one electrode in the red nucleus of cat to be without emotional effect, which leads to the possibility that the present results were caused by the spread of current down to the proximal medial lemniscus.

\section{Some salient features of the data}

At a very gross level, the most salient feature of the present data is the enormous difference they show between hypothalamus and thalamus. According to this material there is no pure avoidance in the hypothalamus, and almost no approach in the thalamus. Even if one takes into account previous reports of pure avoidance in the ventromedial hypothalamus and approach in the anterior thalamus, the fundamental difference is indisputable. At the very least, one is led to wonder about the evolutionary and functional significance of an arrangement which appears to put negative reinforcement mechanisms mainly in thalamic systems and positive mechanisms mainly in hypothalamic systems.

At the level of detail, there are at least three surprising points: (1) the close synaptic relation of the two apparently different motive systems to one another; (2) the likelihood of finding "pure" effects in fiber bundles and "ambivalent" effects in nuclei; and (3) the similarity of thresholds and functions for approach and avoidance behaviors in mid-hypothalamic locations.

Point (1) is illustrated in figure 6 where some of the main tracts involved are portrayed schematically, with the symbols "+" or "-" indicating whether stimulation of the tract produces positive or negative 
reinforcement. This figure suggests that ordinarily, fiber bundles yielding positive reinforcement synapse with those yielding negative reinforcement, and vice versa. The most definitely established findings are that the medial forebrain bundle, the primary input to midline hypothalamic nuclei, yields positive reinforcement; that the nuclei themselves yield ambivalent effects; and that the periventricular system of fibers, which appears to be the main outflow, yields pure negative reinforcement. Figure 6 suggests that similar inversion patterns exist elsewhere in the brain; most of these are suggested by present data but remain to be validated.

The hypothesis of inversion of sign from input to output of hypothalamic nuclei is strengthened by points (2) and (3) above. Ambivalent effects would be achieved by stimulating the nuclei themselves because both afferents and efferents would be affected. In such a case collaterals from the two conflicting systems might yield the conflicted output. Moreover, since the field of afferents and efferents would be relatively homogeneous, one might expect thresholds and functions for the two effects to be similar.

If the data do indeed suggest that there are many direct synaptic relations between elements whose stimulation yields effects of opposite sign, then they imply that one or several of the main projection pathways in this group of systems have inhibitory rather than excitatory function.

One is tempted to think of a Papez--like circuit ('37) consisting of $\mathbf{P}$ fibers (whose stimulation is positively reinforcing) which alternate with $\mathrm{N}$ fibers (whose stimulation is negatively reinforcing), each fiber spontaneously active and each exerting an inhibitory influence on its efferents. If such a system existed, it would function to mediate reciprocal inhibition of positive and negative reinforcement systems, and would imply the existence of some common mechanisms of action between the two systems.

Two reports possibly indicating such reciprocal inhibition come readily to mind. Stimulation of the entorhinal area, which is reported to yield positive reinforcement effects (Brady, '61), causes inhibition of unit response in dorsomedial tegmentum (Adey, '58); but the dorsomedial tegmentum is the area yielding strong negative reinforcement effects in the present and other studies (Olds, '60; Delgado, '55; Delgado, Rosvold and Looney, '56). A similar finding is reported by Bures et al. (61); in dorsomedial tegmentum, unit responses are vastly augmented by cortical spreading depression, and concomitantly, the re-



Fig. 6 Schematic diagram of some of the synaptic relations involved in the present study. For discussion, see "Some salient features of the data." 
sponse frequencies of medial forebrain bundle units are greatly depressed.

If a reciprocal inhibition and a common mechanism of action between the two systems were discovered, earlier drive reduction theories (Miller, '57) might be revived, albeit in a new and possibly inverse guise.

\section{SUMMARY}

Ninety-six bipolar electrodes were implanted in different parts of diencephalic and adjacent structures of rat. Each electrode was tested for approach and avoidance reactions elicited by electric stimulation. The hypothalamus, not the septal area, was shown to be the primary locus of points yielding approach reactions; the thalamus and dorsal tegmentum were shown to be the primary loci of points yielding avoidance reactions.

All of the hypothalamus was involved in the approach system; electric stimulation of points in the lateral or medial forebrain bundle area yielded very intense approach reactions, and avoidance reactions to the same stimuli were mild or absent even when the current was intense or extended over longer periods of time. Electric stimulation in all the other regions of hypothalamus, including the medial section, and stimulation in anterior paraolfactory areas, including the septal area, yielded far milder approach reactions. Stimulation in these areas also yielded avoidance reactions whenever the stimulus was too intense or enduring.

The structures associated with negative reinforcement are not so clearly established, but diffuse thalamic points, points in thalamus and tegmentum associated with the medial lemniscus, and all points in dorsal and periventricular areas of tegmentum yielded pure negative reinforcement regularly.

The relation of these to previous findings is discussed in detail, and the association of negative reinforcement with thalamic structures, and of positive reinforcement with hypothalamic structures, is mentioned.

Finally, the close synaptic relation of fibers which yield behavioral effects of opposite sign, and the tendency of nuclei to yield ambivalent effects, are noted. These facts suggest that the main afferent tracts in this group of systems might be inhibitory rather than excitatory in effect, and that this arrangement might mediate a mechanism of reciprocal inhibition between positive and negative reinforcement processes.

\section{LITERATURE CITED}

Adey, W. R. 1958 Organization of the rhinencephalon. In: Reticular Formation of the Brain, ed. by H. H. Jasper et al., Little, Brown and Co., Boston, 621-644.

Anand, B. K., and S. Dua 1955a Feeding responses induced by electrical stimulation of the hypothalamus in cat. Ind. J. Med. Res., 43: $113-122$.

1955b Blood sugar changes induced by electrical stimulation of the hypothalamus in cat. Ibid., 43: 123-129.

Andersson, B., P. A. Jewell and S. Larrson 1958 An appraisal of the effects of diencephalic stimulation of conscious animals in terms of normal behavior. In: Neurological Basis of Behavior, ed. by G. E. W. Wolestenholme and C. M. O'Connor, Churchill, London, 76-89.

Ariens Kappers, C. V., G. C. Huber and E. C. Crosby 1936 The Comparative Anatomy of the Nervous System of Vertebrates, Including Man. The Macmillan Co., New York, 2 vols.

Bower, G. H., and N. E. Miller 1958 Rewarding and punishing effects from stimulating the same place in the rat's brain. J. Comp. Physiol. Psychol., 51: 669.

Brady, J. V. 1958 Temporal and emotional factors related to electrical self-stimulation of the limbic system. In: Reticular Formation of the Brain, ed. by H. Jasper et al, Little, Brown and Co., Boston.

1961 Motivational-Emotional Factors and Intracranial Self-Stimulation. In: Houston Symposium on Brain Stimulation, Subcortical Integrative Systems, ed. by D. Scheer, Univ. of Texas Press, Austin, 413-430.

Brodie, D. A., J. L. Malis, O. M. Moreno and J. J. Boren 1960 Non-reversibility of the appetitive characteristics of intracranial stimulation. Am. J. Physiol., 199: 707-709.

Brown, G. W., and B. D. Cohen 1959 Avoidance and approach learning motivated by stimulation of identical hypothalamic loci. Ibid., 197: 153-157.

Bures, J., O. Buresova, E. Fifkova, J. Olds, M. E. Olds and R. P. Travis 1961 Spreading depression and subcortical drive centers. Physiologia Bohemoslovenica, 10: 321-331.

Bursten, B., and J. M. R. Delgado 1958 Positive reinforcement induced by intracranial stimulation in the monkey. J. Comp. Physiol. Psychol., 51: 6-10,

Crosby, E. C., and R. T. Woodburne 1951 The mammalian midbrain and isthmus regions. II. The fiber connections. C. The hypothalamotegmental pathways. J. Comp. Neur., 94: 1-32.

DeGroot, J. 1959 The rat forebrain in stereotaxic coordinates. In: Verhandelingen der 
koninklijke neederlandse Akademie van Wetenschappen, LII, No. 4. N. V. Noord-Hollandsche Uitgevers Maatschappij, Amsterdam.

Delgado, J. M. R. 1955 Cerebral structures involved in transmission and elaboration of noxious stimulation. J. Neurophysiol., 18: 261-275.

Delgado, J. M. R., and B. K. Anand 1953 Increase in food intake by electrical stimulation of the lateral hypothalamus. Amer. J. Physiol. 172: $162-168$.

Delgado, J. M. R., and H. Hamlin 1960 Spontaneous and evoked seizures in animals and humans. In: Electrical Studies on the Unanesthetized Brain, ed. by E. R. Ramey and D. S. ODoherty, Paul B. Hoeber, Inc., New York, 133-158.

Delgado, J. M. R., W. W. Roberts and N. E. Miller 1954 Learning motivated by electric stimulation of the brain. Am. J. Physiol., 179: 587593.

Delgado, J. M. R., H. E. Rosvold and E. Looney 1956 Evoking conditioned fear by electrical stimulation of subcortical structures in the monkey brain. J. Comp. Physiol. Psychol., 49: 373-380.

Gastaut, H., R. Naquet, R. Vigouroux and J. Corriol 1952 Provocation de comportements emotionnels divers par stimulation rhinencephalique chez le chat avec électrodes à demeure. Rev. Neurol., 86: 319-327.

Heath, R. G., and W. A. Mickle 1960 Evaluation of seven years' experience with depth electrode studies in human patients. In: Electrical Studies on the Unanesthetized Brain, ed. by E. R. Ramey and D. S. O'Doherty, Paul B. Hoeber, Inc., New York, 214-247.

Hess, W. R. 1949 Das Zwischenhirn, Schwabe, Basel.

1954 Das Zwischenhirn: Syndrone, Lokalisationen, Funktionen. 2nd ed., Schwabe, Basel.

Hodos, W., and E. S. Valenstein 1962 An evaluation of response rate as a measure of rewarding intracranial stimulation. J. Comp. Physiol. Psychol., 55: 80-84.

Jahn, T. L., and V. J. Wulff 1950 Chemoreception. In: Comparative Animal Physiology, W. B. Saunders Co., Philadelphia, Chap. XII, 447450 .

Kaada, B. R. 1951 Somato-motor, autonomic and electrocorticographic responses to electrical stimulation of rhinencephalic and other structures in primates cat and dog. Acta Physiolog. Scand., Suppl., 83, 24: 1-285.

Kopa, J., I. Szabo and E. Grastyan In press. A dual behavioral effect from stimulating the same thalamic point with identical stimulus parameters in different conditional reflex situations. Acta Physiologia Hungarica.

Krieg, W. J. S, 1932 The hypothalamus of the albino rat. J. Comp. Neur, 55: 19-89.

Lilly, J. C. 1958 Learning motivated by subcortical stimulation: the start and stop patterns of behavior. Ir : Reticular Formation of the Brain, Little, Brown and Co., Boston, 705-727.

MacLean, P. D., S. Dua and R. H. Demniston 1961 Dien-mesencephalic loci involved in penile erection and seminal discharge. Fed. Proc., 20 (No. 1, Pt. I), 331. Abstract.

Masserman, J. H. 1941 Is the hypothalamus a a center of emotion? Psychosom. Med., 3: 1-25. 1942 The hypothalamus in psychiatry. Am. J. Psychiat., 98: 633-637.

Massopust, L. C. 1961 Diencephalon of the Rat. In: Electrical Stimulation of the Brain, ed. by D. Scheer, Univ. of Texas Press, Austin, $187 \mathrm{ff}$.

Miller, N. E. 1957 Experiments on motivation. Science, 126: 1271-1278.

Morin, F. 1950 An experimental study of hypothalamic connections in the guinea pig. J. Comp. Neur., 92: 193-213.

Nielson, H. C., R. W. Doty and L. T. Rutledge 1958 Motivational and perceptual aspects of subcortical stimulation in cats. Am. J. Physiol., 194: 427-432.

Olds, J. 1956 A preliminary mapping of elec trical reinforcing effects in the rat brain. J. Comp. Physiol. Psychol., 49: 281-285.

- 1958 Self-stimulation of the brain. Science, 127: 315-324.

_ 1960 Approach-avoidance dissociations in rat brain. Am. J. Physiol., 199: 965-968.

Olds, J., and P. Milner 1954 Positive reinforcement produced by electrical stimulation of septal area and other regions of rat brain. J. Comp. Physiol. Psychol., 47: 419-427.

Olds, J,, and B. Peretz 1960 A motivational analysis of the reticular activating system. EEG Clin. Neurophysiol., 12: 445-454.

Olds, J., and J. C. Sinclair 1957 Self-stimulation in the obstruction box. Am. Psychol, 12: 464. Abstract.

Olds, J., and R. P. Travis 1960 Effects of chlorpromazine, meprobamate, pentobarbital and morphine on self-stimulation. J. Pharmacol. Exp. Therapeut., 128: 397-404.

Olds, J., R. P. Travis and R. C. Schwing 1960 Topographic organization of hypothalamic selfstimulation functions. J. Comp. Physiol. Psychol., 53: 23-32.

Papez, J. W. 1937 A proposed mechanism of emotion. Arch. Neurol. Psychiat. Chicago, 38: $725-743$.

Porter, R. W., D. G. Conrad and J. V. Brady 1959 Some neural and behavioral correlates of electrical self-stimulation of the limbic system. J. Exp. Anal. Behav, 2: 43-55.

Ranson, S. W., and H. W. Magoun 1939 The hypothalamus. Ergbn. Physiol., Biol,, Chem. und Exper. Pharmakol., 41: 56-163.

Reynolds, R. W. 1958 The relationship between stimulation voltage and rate of hypothalamic self-stimulation in the rat. J. Comp. Physiol. Psychol, 51: 193-198.

Roberts, W. W. 1958a Rapid escape learning without avoidance learning motivated by hypothalamic stimulation in cats. Ibid., 51: 391399.

1958b Both rewarding and punishing effects from stimulation of posterior hypothalamus of cat with same electrode at same intensity. Ibid, 51: 400-407. 
1962 Fear-like behavior elicited from dorsomedial thalamus of cat. Ibid, 55: 191197.

Sem-Jacobsen, C. W., and A. Torkildsen 1980 Depth recording and electrical stimulation in the human brain. In: Electrical Studies on the Unanesthetized Brain, ed. by E. R. Ramey and D. S. O'Doherty, Paul B. Hoeber, Inc., New York.

Sidman, M. 1953 Avoidance conditioning with brief shock and no exteroceptive warning signal. Science, 122: 157--158.

Sidman, M., J. V. Brady, J. J. Boren, D. G. Conrad and A. Schulman 1955 Reward schedules and behavior maintained by intracranial selfstimulation. Ibid,, 122: 830-831.
Skinner, B. F, 1948 Superstition in the Pigeon. J. Exp. Psychol., 38: 168-1720.

Stein, L., and O. S. Ray 1959 Self-regulation of brain stimulating current intensity in the rat. Science, 130: 570-572.

Travis, R. P., and J. Olds 1959 Two kinds of escape from midbrain stimulation. Am. Psychol., 14: 430. Abstract.

Wilkinson, H. 1962 Intracranial self-stimulation in cats: a study of the neural basis of emotion. Dissertation submitted to Duke University Anatomy Dept., Durham, North Carolina.

Wurtz, R. H., and J. Olds 1961 Chronic stimulation of amygdaloid complex. Fed. Proc., 20 (No. 1, Pt. 1): 336. Abstract.

\section{PLATES}

Transverse sections through the anterior mesencephalon and forebrain of rat. Cresyl violet stain. $\times 20$. Each section shows the deepest penetration of a given electrode track and the area stimulated just below the track. Stimulation of this area yielded the correlated escape (EH or EL) and approach (SS) functions. EH designates high-threshold escape functions; EL designates low ones. Each function gives the range of five successive daily tests at five current levels; $10,20,30,40,50 \mu \mathrm{a}$ for $\mathbf{S S}$ and EH functions, and $10,15,20,25,30 \mu \mathrm{a}$ for EL functions. The $\mathrm{X}$ axis is in $\mu$ a, from 10 to 30 or 50 inclusive; the $Y$ axis is in eight-minute response rates, from 0 to 800 inclusive. The $S S$ and $E$ numbers above each graph denote the maximum eight-minute response rate for the correlated electrode placement.

Cases yielding similar scores on either approach or escape tests or both are grouped together to form a single figure. Cases yielding scores of $200 \mathrm{rp} / 8$-min or higher on approach tests but failing on escape tests are shown on "approach" figures. Cases yielding scores of $180 \mathrm{rp} / 8 \mathrm{-min}$ or higher on escape tests but failing on approach tests are shown on "escape" figures. Cases meeting these criterial levels on both tests are shown on "ambivalent" figures. Cases meeting neither criterion are shown on plates 10 and 11 , where directions of possible effect are indicated.

Sections are arranged with the more anterior ones at the top of a figure, and (wherever possible) proximal points placed side by side. Above each section are the three coordinates (given in $\mathrm{mm}$ from bregma) used to implant the electrode (e.g., -319 indicated $3 \mathrm{~mm}$ posterior from bregma, $1 \mathrm{~mm}$ latcral, and $9 \mathrm{~mm}$ deep). Abbreviations above each section indicate the structures that appear to have been stimulated. Numbers and letters in the plate margins designate rows (alphabetically) and columns (numerically). Each case is assigned a number which designates its plate, its column, and its row (e.g., 1-2A is the case shown in plate 1 , column 2, row A). This identification number is redundantly placed on the photomicrograph to facilitate location of the case on the plate; in table 2 it is used to facilitate cross-location of cases from the table to the plates. 
AAA, Area amygdaloidea anterior

$A B$, Nucleus amygdaloideus basalis

$A C B$, Nucleus accumbens septi (Area parolfactoria lateralis)

ACE, Nucleus amygdaloideus centralis

ACO, Nucleus amygdaloideus corticalis

AD, Nucleus anterodorsalis thalami

AHA, Area anterior hypothalami

AL, Nucleus amygdaloideus lateralis

AM, Nucleus anteromedialis thalami

AME, Nucleus amygdaloideus medialis

Ant Cingulate, Anterior cingulate

ARH, Nucleus arcuatus hypothalami

AT, Anterior group of thalamic nuclei

AV, Nucleus anteroventralis thalami

BCA, Nucleus proprius commissurae anterioris (Bed nucleus)

BCI, Brachium colliculi inferioris

BCS, Brachium colliculi superioris

BST, Nucleus proprius striae terminalis (Bed nucleus )

$\mathrm{CA}$, Commissura anterior

CC, Corpus callosum

CE, Capsula externa

$\mathrm{CH}$, Commissura hippocampi (Commisura fornicis )

CI, Capsula interna

CLA, Claustrum

$\mathrm{CN}$, Cingulate

CO, Chiasma opticum

CP, Commissura posterior

CPU, Nucleus caudatus/Putamen

CS, Colliculus superior

CSC, Commissura colliculi superioris

D, Nucleus Darkschewitz

DBB, Gyrus diagonalis (Diagonal band of Broca)

DBC, Decussatio brachiorum conjunctivorum

DL, Dorsolateral

$D M$, Dorsomedial

DMH, Nucleus dorsomedialis hypothalami

DTV, Decussatio tegmenti ventralis (Forel)

$\mathrm{EH}$, Rate of escape over eight-minute period from 10 to $50 \mu \mathrm{a}$

EL, Rate of escape over eight-minute period, from 10 to $30 \mu \mathrm{a}$

FD, Gyrus dentatus (Fascia dentata)

FF, Fields of Forel

FI, Fimbria hippocampi

FLD, Fasciculus longitudinalis dorsalis (Schutz)

FLM, Fasciculus Iongitudinalis medialis

FR, Fissura rhinalis

FX, Fornix (Corpus, columna)

GM, Corpus geniculatum mediale

GP, Globus pallidus

H, Habenula

HL, Nucleus habenularis lateralis

HM, Nucleus habenularis medialis

HP, Tractus habenulo-interpeduncularis (Fasciculus retroflexus) (Meynert)

HPC, Hippocampus (Cornu Ammonis)

HTH, Hypothalamus

IP, Nucleus interpeduncularis

$L$, Lateral

LHA, Area lateralis hypothalami
Limbic, Limbic lobe

LM, Lemniscus medialis

LS, Nucleus lateralis septi

LT, Nucleus lateralis thalami

LTP, Nucleus lateralis thalami pars posterior

$\mathrm{M}$, Foramen interventriculare (Monro)

$M$, Medial

Meninges, Meninges

MD, Nucleus mediodorsalis thalami

MFB, Fasciculus medialis telencephali (Medial forebrain bundle)

ML, Nucleus mamillaris lateralis

MM, Nucleus mamillaris posterior

M Rad, Medial thalamic radiation to cortex

MS, Nucleus medialis septi

MT, Tractus mamillo-thalamicus (Vicq d'Azyr)

MTT, Mamillo-thalamic tract

NC, Neo-cortex

NCP, Nucleus proprius commissurae posterioris (Bed nucleus)

NPT, Nucleus posterior thalami

NR, Nucleus ruber

OT, Tractus opticus

Out, Out of the brain

$P$, Pons

$P$, Posterior

Para $\mathrm{O}$, Paraolfactory tract

PC, Pedunculis cerebri

PF, Nucleus parafascicularis thalami

$\mathrm{PH}$, Nucleus posteria hypothalami

PIR, Cortex piriformis

PM, Peduncularis mamillaris

PMD, Nucleus premamillaris dorsalis

POA, Area preoptica (medialis, lateralis)

PRT, Area pretectalis

PV, Nucleus paraventricularis thalami

PVG, Substantia grisea periventricularis (centralis)

PVH, Nucleus paraventricularis hypothalami (enfiliformis)

RE, Nucleus reuniens thalami

RF, Formatio reticularis (mesencephali)

RT, Nucleus reticularis thalami

SM, Stria medullaris thalami

SN, Substantia nigra

SO, Nucleus supraopticus hypothalami

SOC, Supraoptic commissures

SS, Self-stimulation rate over eight-minute period, 10-50 $\mu \mathrm{a}$

ST, Stria terminalis (Taenia semicircularis)

SUM, Area supramamillaris

TOL, Lateral olfactory tract

TP, Tractus tuberculo-piriformis

TUO, Tuberculum olfactorium

$\mathrm{V}$, Ventriculus cerebri

VA, Nucleus ventralis thalami pars anterior

VD, Nucleus ventralis thalami pars dorsomedialis

VE, Nucleus ventralis thalami

$V L$, Ventrolateral

VM, Nucleus ventralis thalami pars medialis

VMH, Nucleus ventromedialis hypothalami

VTN, Nucleus ventralis tegmenti (Tsai)

$\mathrm{ZI}$, Zona incerta

\footnotetext{
* Based primarily upon the abbreviations used by DeGroot ('59).
} 
APPROACH ONLY - HIGH

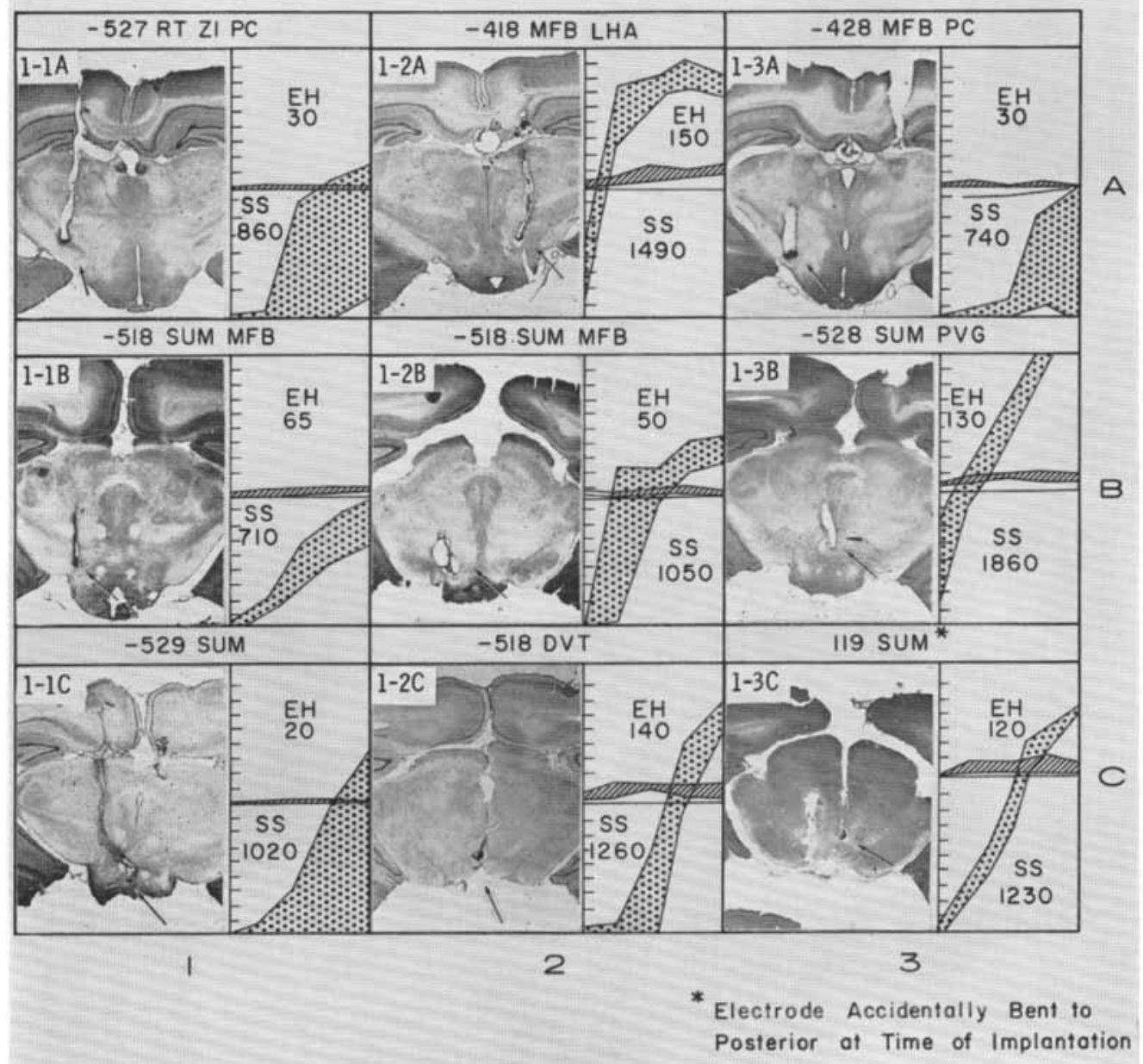

Nine of the ten cases yielding maximum approach scores (700 rp/8-min and higher) and escape scores of less than 180. Animal No. 1-0A, whose data appear in figure 3 , is the tenth case belonging to this group. 


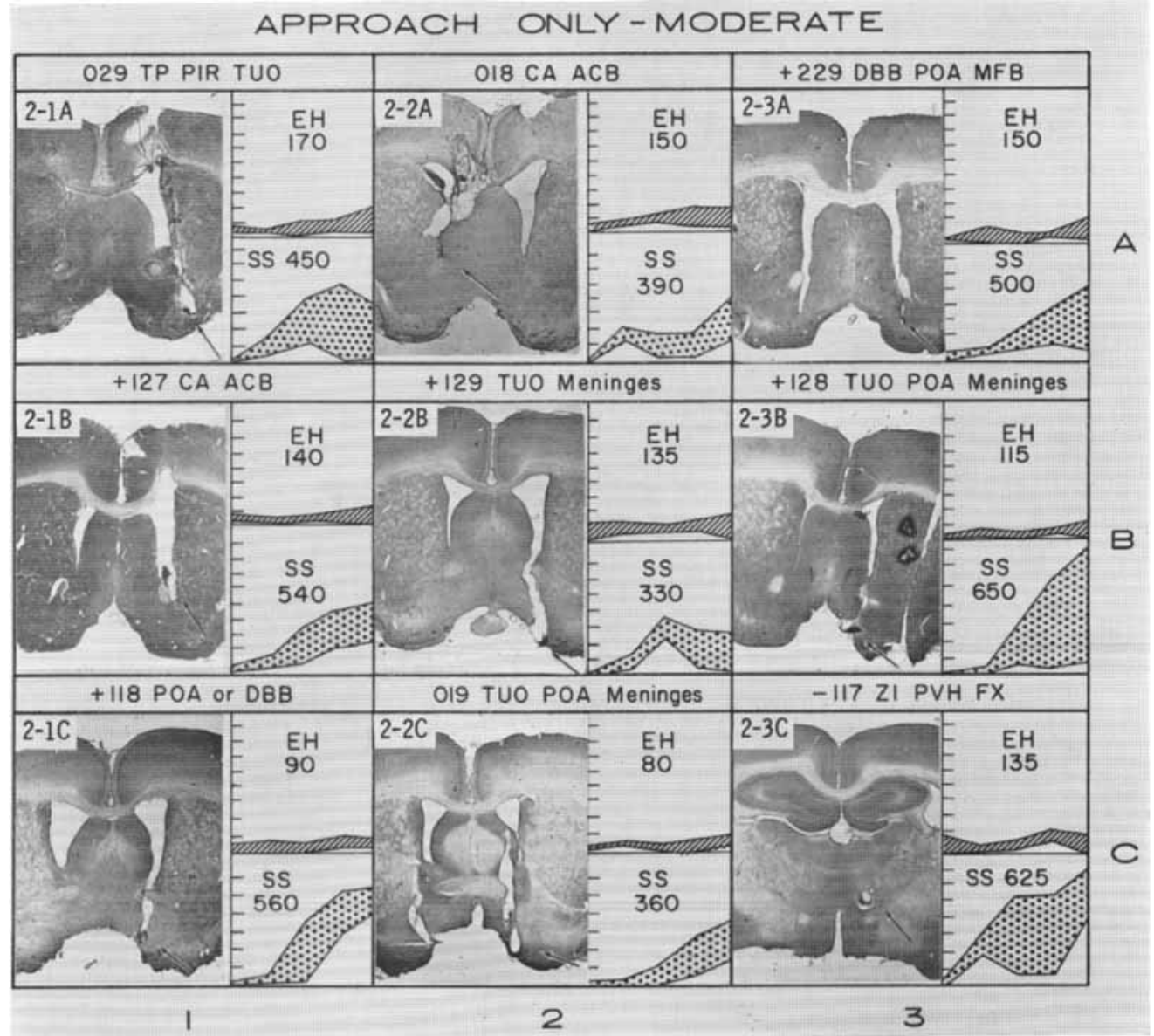

Nine cases yielding moderate approach scores (301-699 rp/8-min) and failing to meet the escape criterion. 


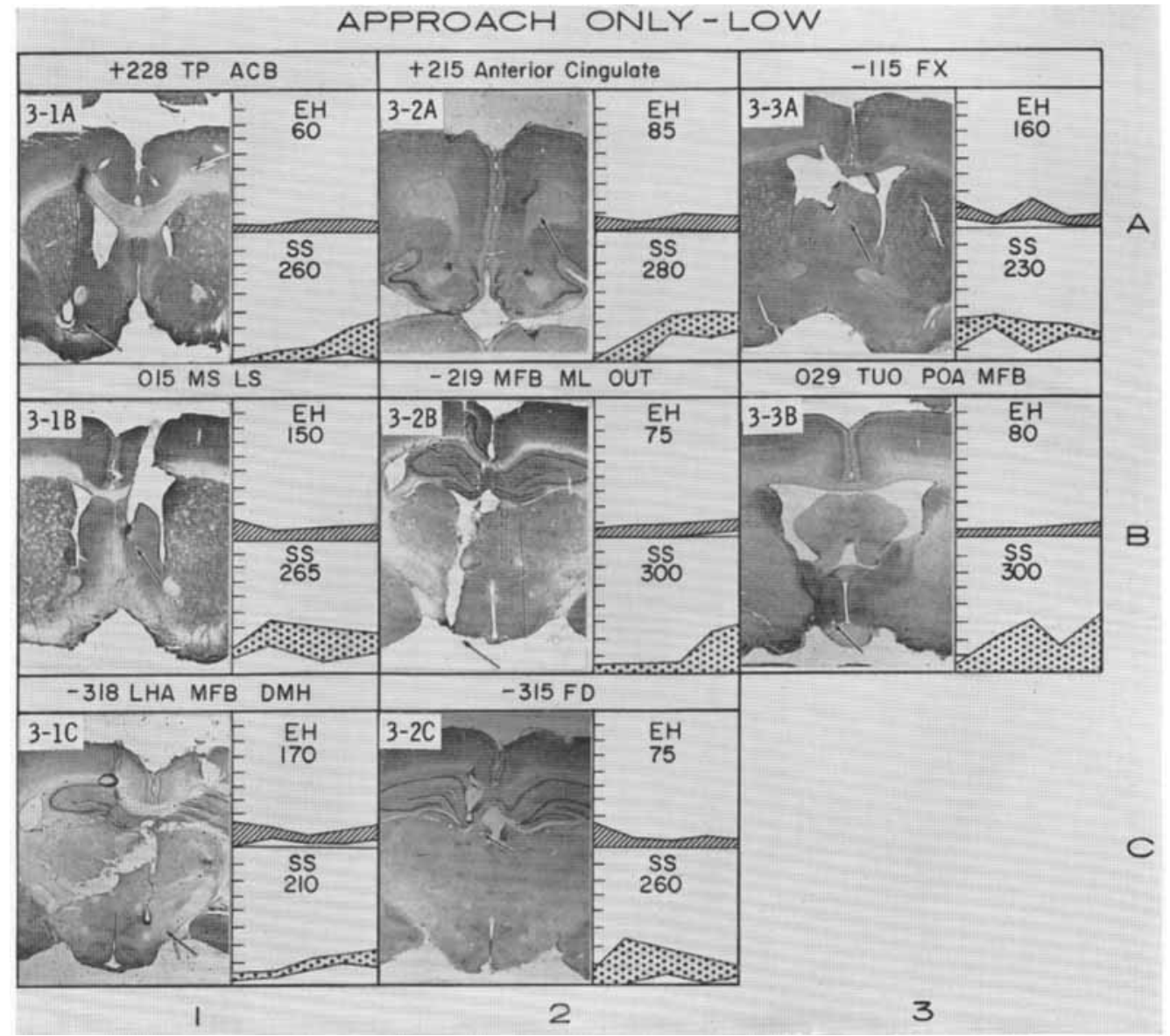

Eight cases yielding low approach scores (200-300 rp/8-min) and failing to meet the escape criterion. 
ESCAPE ONLY-HIGH (MORE ANTERIOR PLACEMENTS)

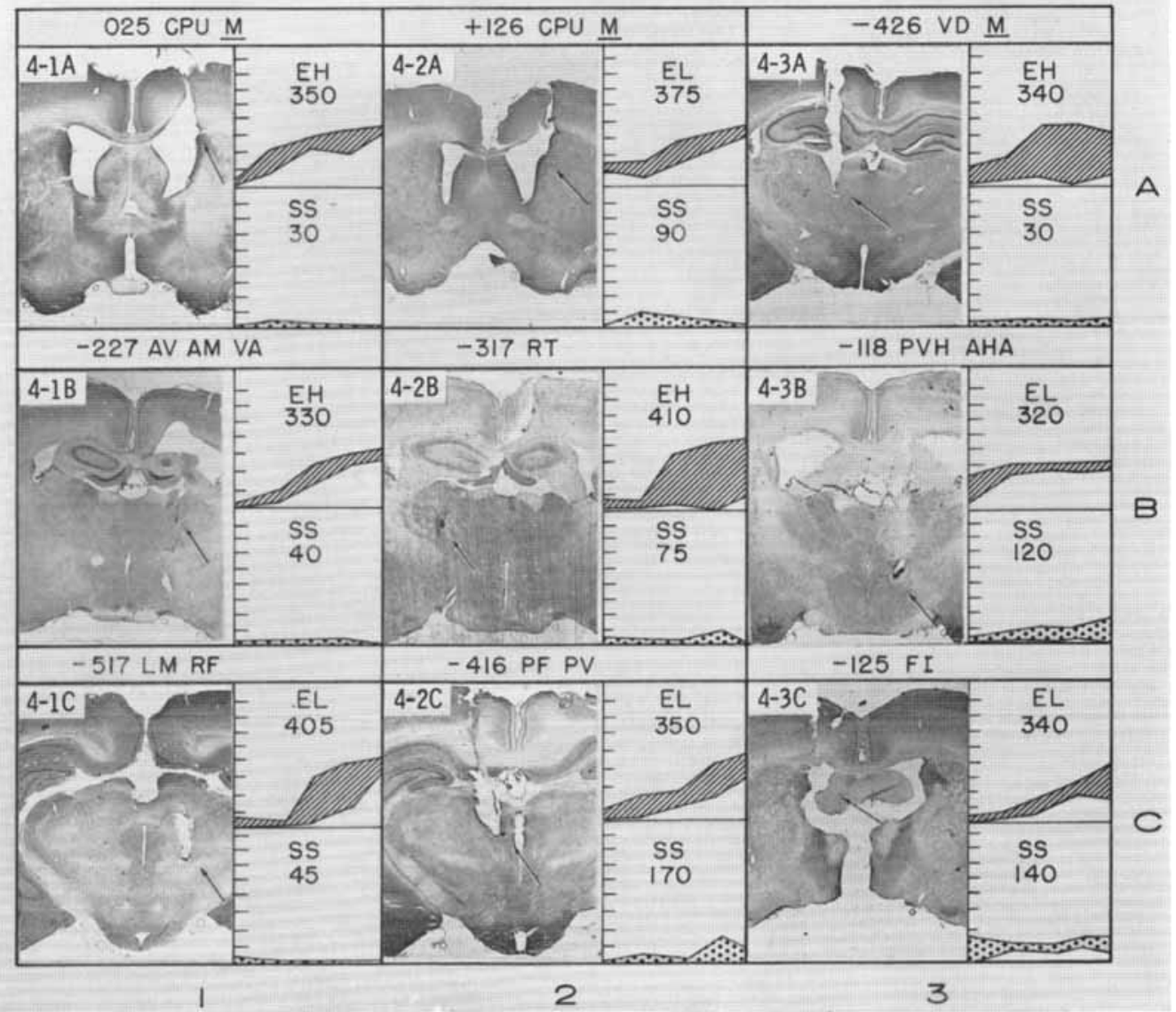

Nine of the 18 cases yielding maximum escape scores ( $300 \mathrm{rp} / 8-\mathrm{min}$ and higher) and no approach. These are the cases with the more anterior electrode placements; the other nine are shown in plate 5 . 
ESCAPE ONLY-HIGH (MORE POSTERIOR PLACEMENTS)

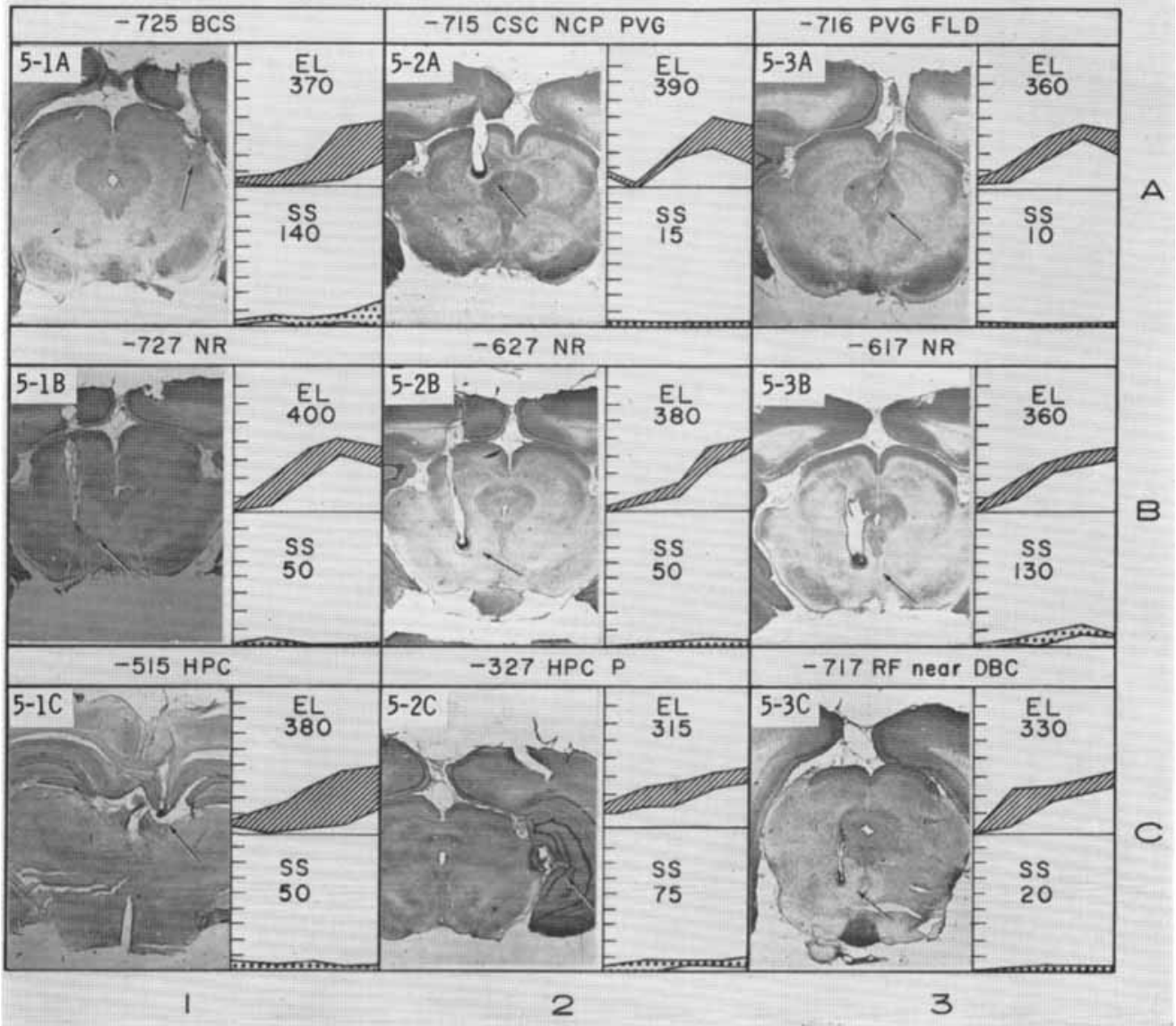

Nine of the 18 cases yielding maximum escape scores ( $300 \mathrm{rp} / 8-\mathrm{min}$ and higher) and no approach. These are the cases with the morc posterior electrode placements; the other nine are shown in plate 4. 


\section{ESCAPE ONLY-LOWIMORE ANTERIOR PLACEMENTS)}

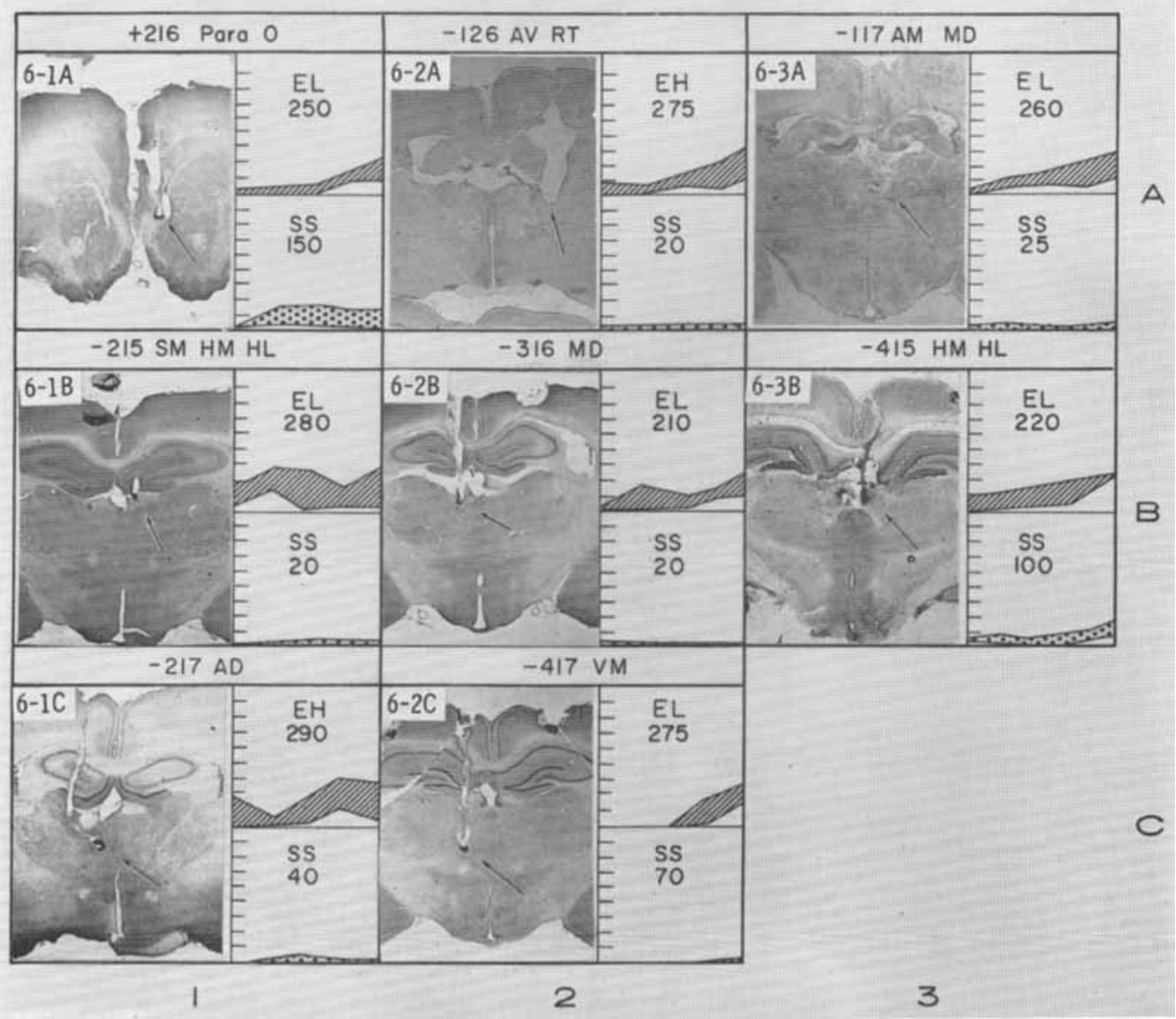

Eight of the 16 cases yielding low but significant escape scores (180-300 rp/8-min) and no approach. These are the cases with the more anterior electrode placements; the other nine are shown in plate 7 . 
ESCAPE ONLY-LOW (MORE POSTERIOR PLACEMENTS)

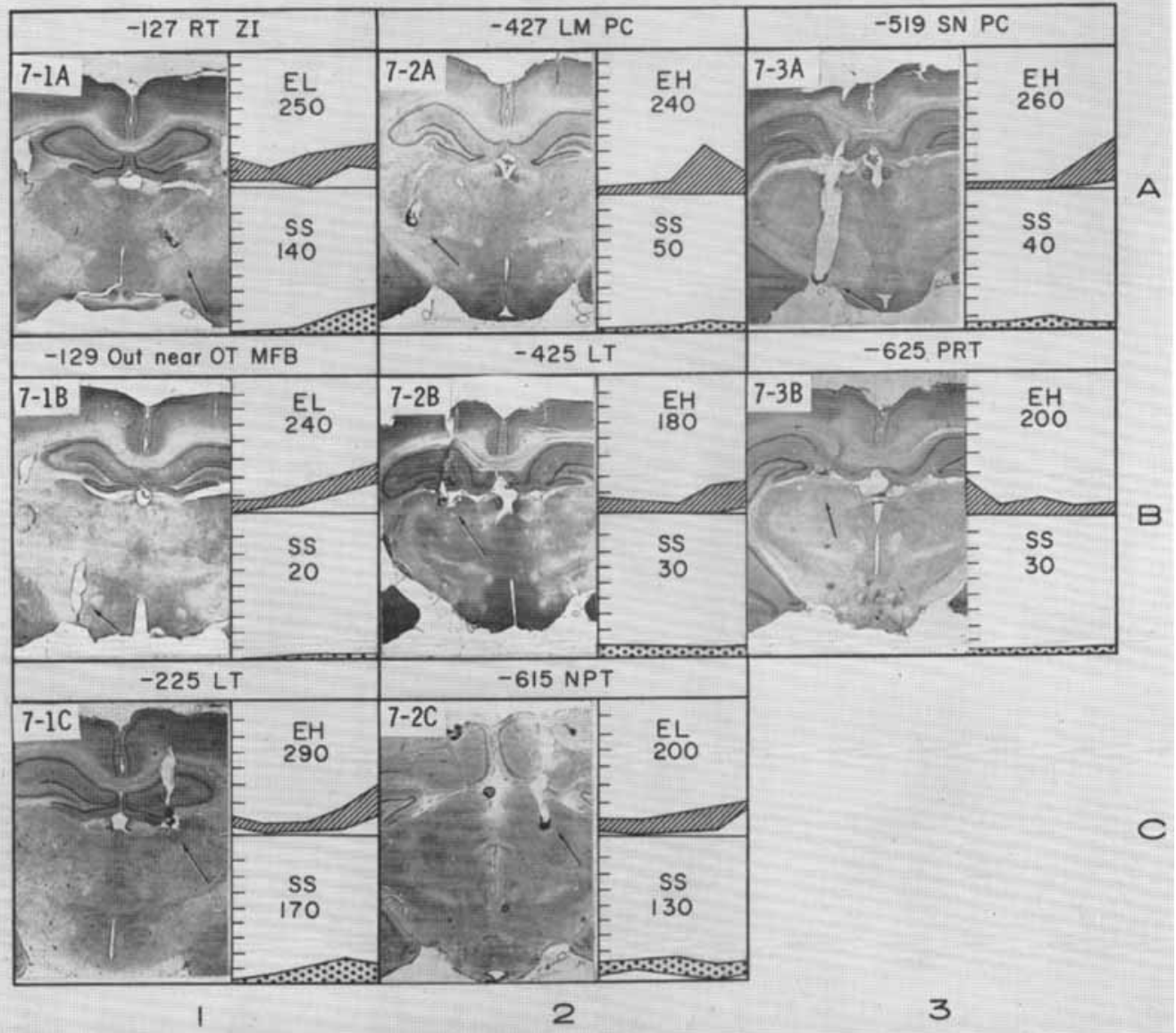

Eight of the 16 cases yjelding low but significant escape scores and no approach. These are the cases with the more posterior electrode placements; the other nine are shown in plate 6. 


\section{AMBIVALENT (MORE ANTERIOR PLACEMENTS)}

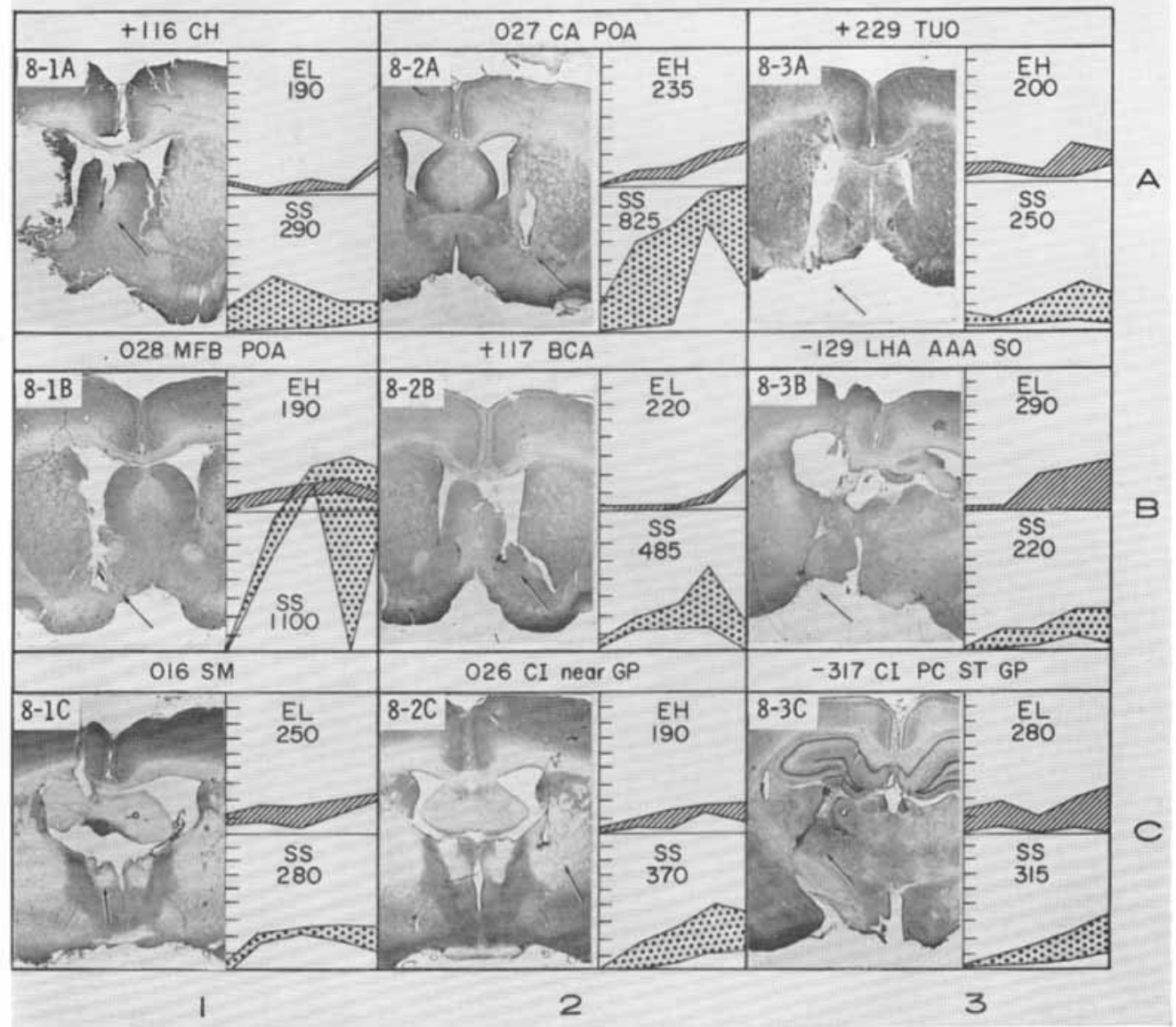

Nine of the 18 cases yielding both escape scores above 180 and approach scores above 200 rp/8-min. These are the cases with the more anterior electrode placements; the other nine are shown in plate 9 . 


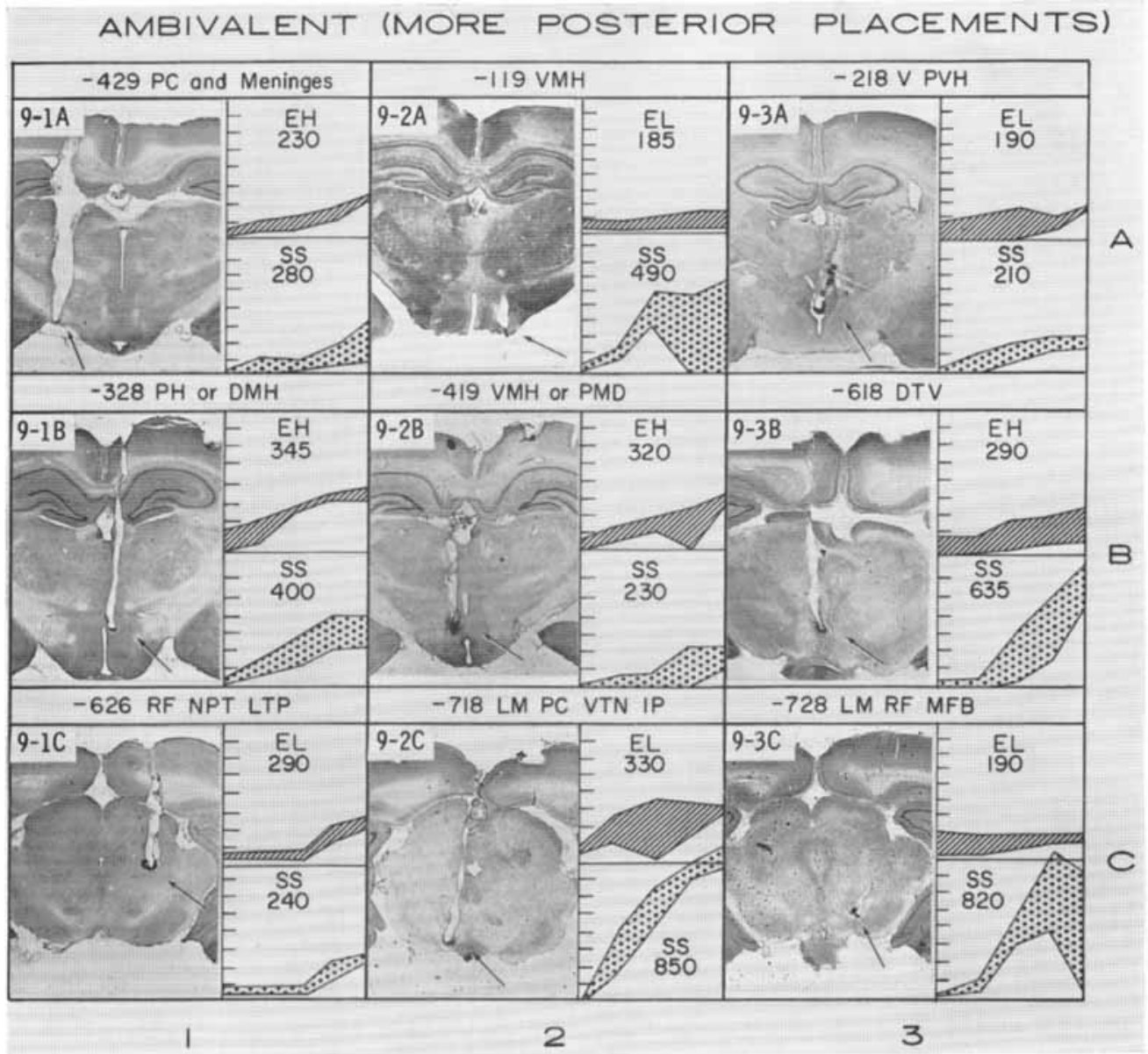

Nine of the 18 cases yielding both escape scores above 180 and approach scores above $200 \mathrm{rp} / 8$-min. These are the cases with the more posterior electrode placements; the other nine are shown in plate 8 . 


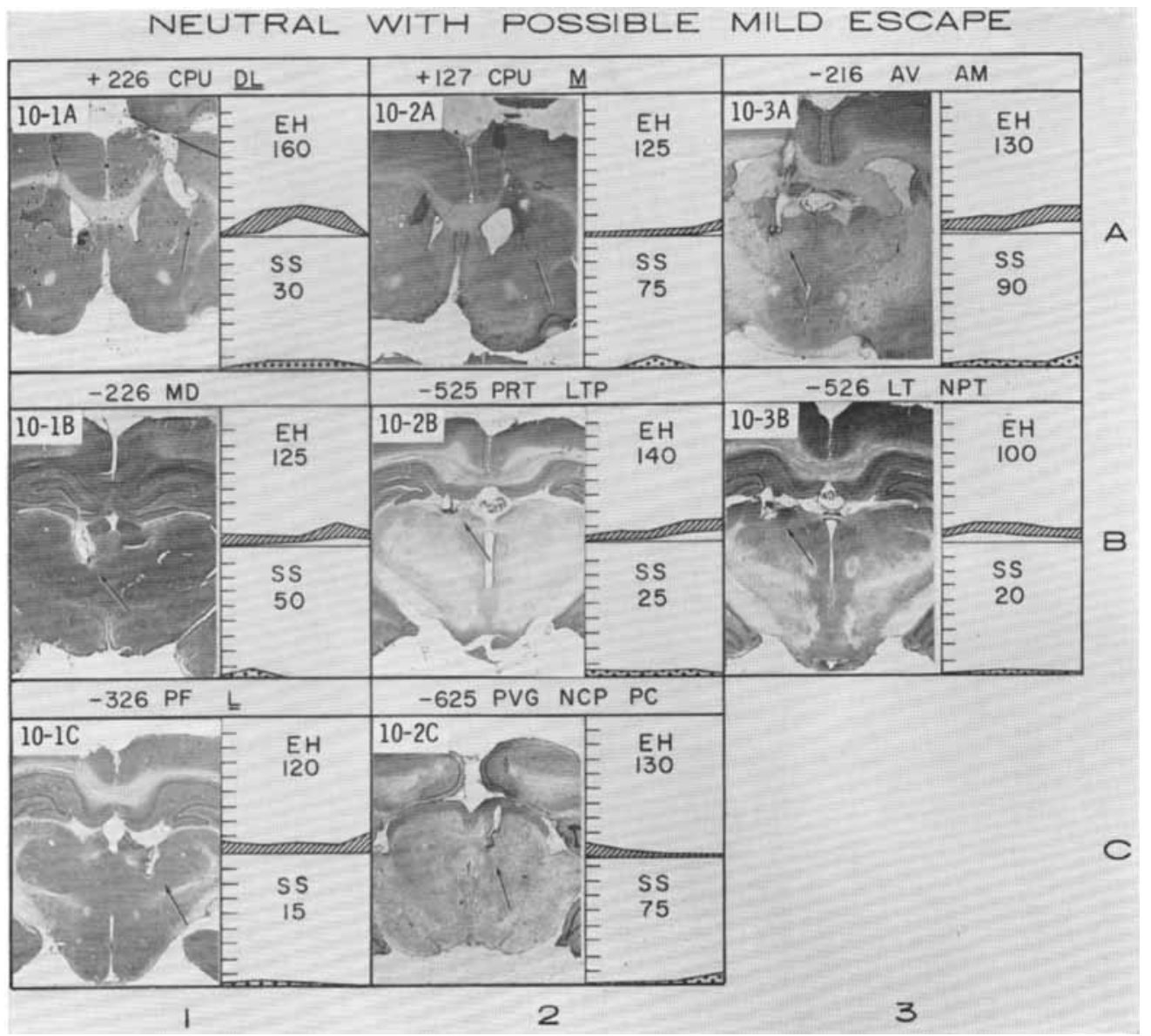

Eight of the 17 cases yielding neither escape scores above 180 nor approach scores above 200 $\mathrm{rp} / 8$-min. These are the eight cases which meet the weak escape criterion (100 $\mathrm{rp} / 8-\mathrm{min})$ and no approach. The other nine are shown in plate 11. 


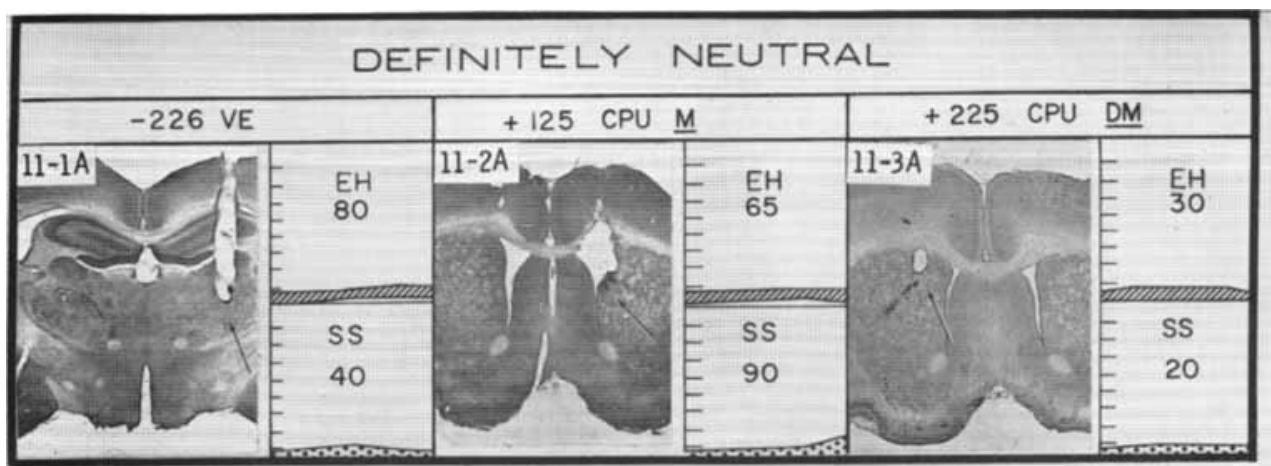

A

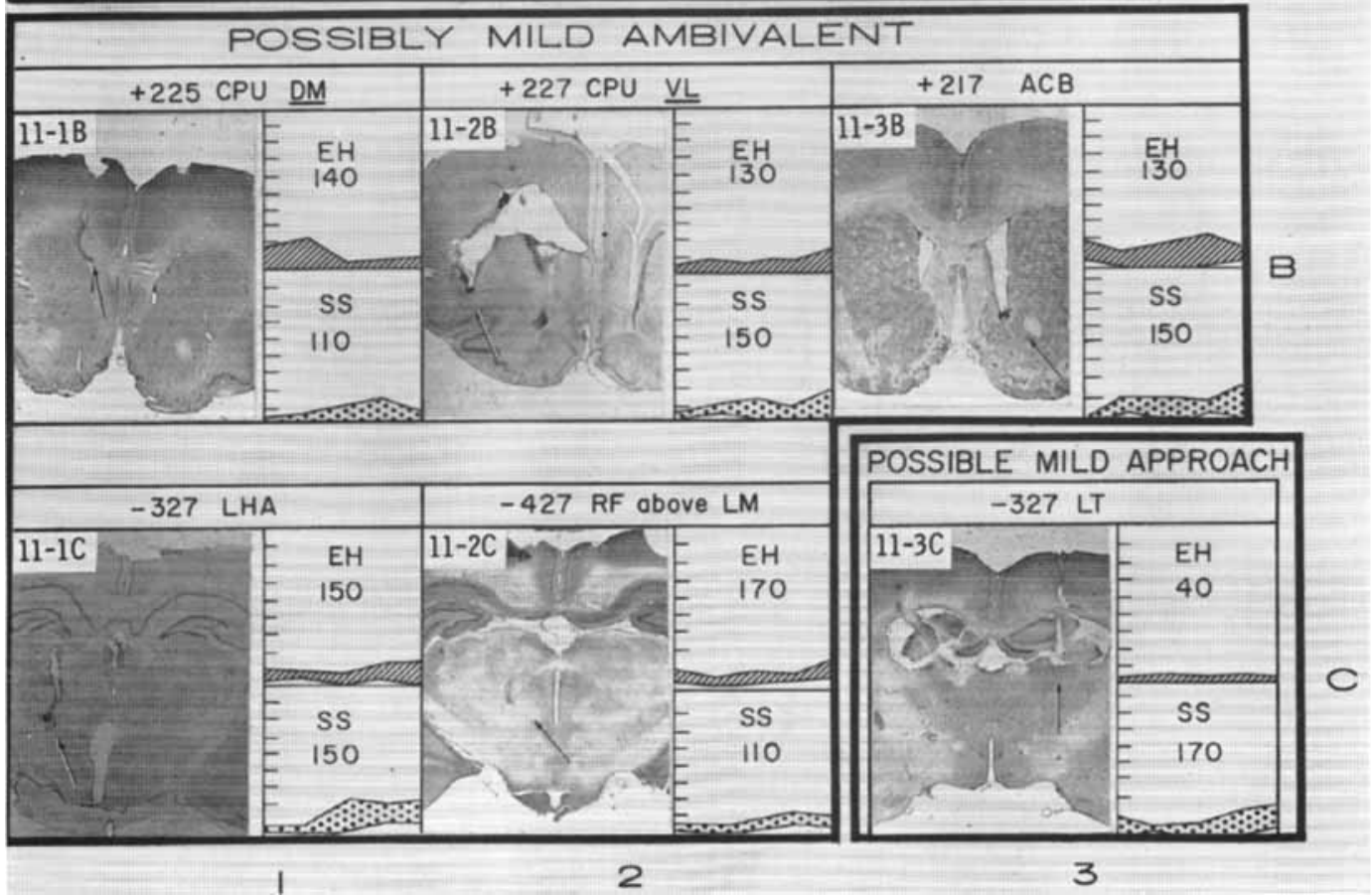

Nine of the 17 cases yielding neither escape scures above 180 nor approach scores above $200 \mathrm{rp} /$ 8-min. Only the three cases in row A fail to meet the weak criterion ( $100 \mathrm{rp} / 8-\mathrm{min}$ ) on at least one of the reinforcement tests. The next five cases are called "possible mild ambivalent" because they surpass the weak criterion on both approach and escape tests. The last case, 11-3C, meets the weak approach criterion but not the weak escape criterion. 